\title{
¿La justicia de la 'mano muerta del pasado'? Sobre la interpretación dinámica y el principio de legalidad penal ${ }^{1}$
}

\author{
Justice from 'The Dead Hand of Past'? On Evolving Interpretation and the Princi- \\ ple of Legality in Criminal Matters
}

\author{
LUCIANO D. LAISE ${ }^{2}$ \\ CONICET, Argentina
}

\begin{abstract}
RESUMEN El problema de la 'mano muerta del pasado' refiere a la cuestión que se plantea en teoría de la interpretación acerca del grado de fidelidad que se le debe a quienes redactaron y aprobaron una disposición jurídica. Esta tesis suele ser discutida intensamente por quienes defienden una interpretación dinámica de las normas y disposiciones que reconocen derechos fundamentales. Sin embargo, esto introduce un reto complicado al momento de interpretar el alcance del principio de legalidad penal, porque de la pretensión de asegurar la eficacia de las normas penales no podría derivarse alguna clase de aplicación analógica de las disposiciones jurídicas. Por ende, cabría preguntarse, ¿es la interpretación dinámica irreconciliable con el principio de legalidad que modela al derecho penal propio de un Estado de Derecho? ¿Es la interpretación dinámica una excusa para eludir la prohibición de aplicación analógica de normas penales? Este trabajo pretende brindar una respuesta a tales interrogantes.
\end{abstract}

\footnotetext{
1. El autor reconoce y agradece a Fabio Pulido, Pablo Rivas, David Ramírez Pabón, Paulo Nestares, Edgar Hernán Fuentes-Contreras, Sergio Morales, Gustavo Manzó, Leonardo Guarín y Juan Sebastián Bohorquez por las sugerencias y/o discusión de algunas cuestiones que han modelado y pulido a las ideas desarrolladas en este trabajo. Especialmente agradezco a los participantes del Seminario del Dpto. de Teoría Jurídica y de la Constitución de la Universidad de La Sabana (Colombia) porque en una de sus sesiones tuve la oportunidad de discutir una versión previa de esta investigación. A Frederico Bonaldo le reconozco haber sido quien me incitó a reflexionar sobre el caso brasileño que se emplea en este trabajo.

2. Doctor en Derecho (U. Austral, Argentina). Investigador de planta del Consejo Nacional de Investigaciones Científicas y Técnicas (CONICET), lugar de trabajo: Departamento de Ciencias Sociales, Jurídicas y Económicas, Universidad Nacional de Chilecito, 9 de Julio $\mathrm{N}^{\circ}$ 22, Chilecito, La Rioja, Argentina. ORCID: https://orcid.org/0000-0003-4249-5948. E-Mail: lucianolaise@conicet.gov.ar.
} 
PALABRAS CLAVE Garantías constitucionales del derecho penal; prohibición de analogía; justicia; seguridad jurídica; interpretación de la ley penal.

ABSTRACT The 'dead hand of the past' problem refers to an issue posed in the theory of legal interpretation, as to how far we should remain faithful to those who adopted our current constitutional provisions. This claim is widely discussed by those who defend some sort of evolving interpretation of basic rights. Nevertheless, this approach introduces a subtle challenge when interpreting the extension of the principle of legality in criminal matters, as the intention of achieving effectiveness through criminal laws should not be derived from any kind of analogical application of the law. We may therefore wonder: Is evolving interpretation necessarily incompatible with the principle of legality in criminal issues, as required by Rule of Law? Is evolving interpretation plainly an excuse for eluding prohibitions of analogical application of criminal provisions? This article attempts to provide answers to these questions.

KEYWORDS Constitutional guarantees of criminal law; prohibition of analogy; justice; legal security; interpretation of criminal provisions.

\section{Introducción: proyecciones del principio de legalidad sobre la interpretación dinámica de las normas penales}

Uno de los dos principios fundamentales del derecho penal es el principio de legalidad - junto con otro, el principio de culpabilidad ${ }^{3}$ - . El curso de la historia ha revelado que se trata, en efecto, de los criterios legitimadores de la coacción penal. Estos principios funcionan como límite a la coacción para así concretar la protección de la libertad individual en un marco de paz social ${ }^{4}$. El principio de legalidad, de entre esos principios legitimantes, se podría decir que ocupa un lugar especial en la historia del derecho penal; aún más, se trataría de uno de los principios más antiguos del derecho 5 en general.

Ahora bien, el principio de legalidad en cuestiones penales implica cuatro prohibiciones: i) la prohibición de cláusulas generales ${ }^{6}$; ii) la prohibición de aplicación analógica; iii) la prohibición de aplicación retroactiva de leyes posteriores a los he-

3. YACOBUCCI (2002) p. 126.

4. ROXIN (1997) p. 137.

5. HALLEVY (2010) p. ix.

6. Las 'clasulas generales' son una de las principales dificultades que enfrenta la concretización del principio de legalidad penal. Porque, en efecto, "la proliferación de tipificaciones con límites difusos, con elementos valorativos etizantes, con referencias de ánimo, con omisiones u ocultamientos del verbo típico, etc., son otras formas de debilitar o cancelar la legalidad penal". ZAFFARONI (1998) p. 32. 
chos que se imputan; iv) la prohibición de fundamentación de la condena en derecho diverso del que dimana de la ley en sentido formal $-p$. e., costumbre- ${ }^{7}$. Si bien todas estas prohibiciones están íntimamente vinculadas entre sí y, por ende, no siempre son claramente distinguibles en el nivel o plano operativo-práctico $-p$. e., la aplicación analógica del derecho bien podría implicar la aplicación de una ley retroactivamente creada mediante decisiones judiciales-, lo cierto es que este trabajo pondrá el foco de interés en la aplicación analógica del derecho.

De hecho, la prohibición de una aplicación analógica del derecho está francamente en tensión con la doctrina de la interpretación evolutiva o dinámica del derecho ${ }^{8}$. La pretensión de concebir a los tipos penales como un "árbol viviente capaz de crecer y expandirse dentro de sus límites naturales" ${ }^{\prime}$ es algo que actualmente podrá tener mucho atractivo en materia constitucional ${ }^{10}$, pero que resulta problemático para la dogmática penal. Esto último se revela, por ejemplo, en el apego a la interpretación literal que plantean algunos doctrinarios del derecho penal ${ }^{11}$, lo que no escapa de aquello que - parafraseando libremente a Hart- podríamos llamar el 'noble sueño'; es decir, la loable pero ingenua creencia de que es posible resolver todos los casos posibles a partir de una dilucidación del tenor literal de las formulaciones normativas ${ }^{12}$.

El abordaje de este problema no es sencillo porque un compromiso robusto con el principio de legalidad que rechace toda clase de interpretación dinámica por ser un mero ocultamiento de una aplicación analógica del derecho podría complicar la eficacia de ciertas normas penales. Y, del lado contrario, una pretensión concentrada unilateralmente en la eficacia podría volver en letra muerta a todas las garantías iusfundamentales que se desprenden del principio de legalidad. Estamos frente a una cuestión en la que cortar o, siquiera tocar, el cable de un modo incorrecto podría hacer volar por los aires a la aspiración de conciliar armónicamente a las garantías cons-

\section{$\overline{\text { 7. BACIGALUPO (1999) p. } 76 .}$}

8. Cabe aclarar que en el presente trabajo se utilizarán como expresiones sinónimicas tanto interpretación dinámica' como 'interpretación evolutiva'. Más adelante se explicará la razón por la que en este trabajo se han omitido otras terminologías similares. INFRA, 4.2. "Distinciones preliminares: la interpretación evolutiva o dinámica y la interpretación viviente".

\section{Edwards v. Attorney General of Canada (1930) p. 136.}

10. WALUCHOW (2007) p. 64.

11. DONNA (1996) p. 12; MIR PUIG (2006) p. 115.

12. La expresión 'noble sueño' en Hart se refiere puntualmente a la ingenua creencia de que los jueces no participan en modo alguno en el proceso de creación del derecho. Aquí 'noble sueño' se utiliza con meros efectos retóricos, ya que solo se pretende remarcar lo ingenuo que resulta la defensa de la interpretación literal, al igual que el célebre profesor inglés consideraba que la jurisprudencia mecánica era demasiado naíf. HART (1976) p. 980 y ss. En un sentido similar, Atienza plantea que el positivismo normativista describía al Derecho como una realidad dada de antemano, la cual tan solo aguardaría a ser (re)conocida por los juristas prácticos o teóricos. ATIENZA (2013) p. 107. 
titucionales de la persona frente al ius puniendi, lo cual derivaría en una entera subordinación del principio de legalidad a la eficacia punitiva o, en su extremo opuesto, un compromiso con la legalidad que le da a la espalda a las consecuencias o resultados.

Las consideraciones sobre la vinculación entre las garantías constitucionales y la interpretación dinámica de la ley penal dependen, en buena medida, del sistema constitucional que se esté examinando. En tal sentido quisiera dejar en claro que el foco de esta investigación estará orientado a iluminar un sistema de control de constitucionalidad de tipo difuso como es el caso estadounidense o argentino. Sin perjuicio de que, mutatis mutandi, no poco de lo que aquí se examinará podría echar luz sobre la inaplicación de normas legales que hacen los jueces ordinarios en los casos en que estas resultan contrarias a la constitución, tal como acontece en sistemas de control de constitucionalidad de tipo mixto ${ }^{13}$.

La estructura argumentativa de este artículo será la siguiente: i) se elaborará una explicación sobre el sentido constitucional del principio de legalidad penal; ii) se reconstruirá lo que significa una interpretación dinámica de las disposiciones jurídico-penales; iii) se determinará el grado de compatibilidad entre la interpretación dinámica de normas penales y el principio de legalidad; iv) se efectuará una serie de consideraciones para lograr identificar criterios que permitan distinguir una aplicación analógica del derecho penal de una interpretación dinámica de las disposiciones jurídico-penales. v) Se elaborará un balance crítico de los resultados de esta investigación. Finalmente, vi) se recapitularán las principales contribuciones de este trabajo en un apartado conclusivo.

\section{El sentido del principio de legalidad: entre la eficacia del ius puniendi y una garantía constitucional frente a la aplicación arbitraria del derecho penal}

El principio de legalidad es un punto de partida virtualmente incuestionable para toda reflexión que involucre al poder punitivo del Estado, pero que hoy parece estar en crisis $^{14}$. De hecho, la flexibilización del principio de legalidad es uno de los malestares en que se revela la crisis general del derecho penal ${ }^{15}$. Esto se ha manifestado paradigmáticamente en la discutida y problemática sentencia 'Simón', en la que se formuló una declaración de inconstitucionalidad de las leyes argentinas de 'obediencia debida y punto final' (Ley Nacional 23.492/86), las cuales otorgaron una amnistía a los

13. Para una explicación básica o introductoria del control de constitucionalidad difuso: HIGHTON (2010) pp. 108-109. Para una caracterización del sistema de control de constitucionalidad mixto: BREWER-CARIAS (1995) p. 9.

14. ROSLER (2017) p. 67. En un sentido similar, SILVA SÁNCHEZ (2008) p. 206.

15. YACOBUCCI (2006) p. 1074. 
agentes de las fuerzas militares que cometieron crímenes de lesa humanidad; excepto a sus máximos responsables ${ }^{16}$.

Tal es la relevancia del principio de legalidad que la Corte Suprema de Justicia de la Nación Argentina se ha referido a él con estas palabras: "es una de las garantías más preciosas consagradas por la constitución la de que ningún habitante de la Nación pueda ser penado sin juicio previo fundado en ley anterior al hecho del proceso" ${ }^{17}$. Con todo, tal como lo plantea Bacigalupo, su vigencia material es tan discutida como problemática fuera del plano discursivo ${ }^{18}$. Por ende, el desafío consiste en pasar del reconocimiento formal a la realización material del principio de legalidad. Dicho de otra manera, el principio de legalidad requiere más concreción práctica que alabanzas dogmáticas o de formulaciones normativas que fomenten su aplicación en sede judicial.

En cualquier caso, el sentido mismo del principio legalidad está íntimamente enlazado con la noción de seguridad jurídica, lo que depende de la fijación del contenido del derecho penal a través de una serie de disposiciones jurídicas escritas, ciertas, estrictas y previas al hecho que se juzga ${ }^{19}$. El aseguramiento de la libertad frente al poder coactivo del Estado, en último término, pende de la convicción arraigada en los ciudadanos de que estos no serán condenados arbitrariamente, sino en la estricta medida en que haya una sentencia basada en una ley previa que prohíbe la conducta imputada ${ }^{20}$.

De hecho, el sistema constitucional argentino ha recogido el principio de legalidad en materia penal a través del artículo 18 de la Constitución Nacional, el cual dispone que "Ningún habitante de la Nación puede ser penado sin juicio previo fundado en ley anterior al hecho del proceso, ni juzgado por comisiones especiales, o sacado de los jueces designados por la ley antes del hecho de la causa" ${ }^{21}$. Además, el texto cons-

16. Simón, Julio Héctor y otros s/ privación ilegítima de la libertad (2005). Para una visión crítica de la estrategia argumentativa desplegada por la Corte Suprema de Justicia de la Nación Argentina, ELIAS (2008) p. 632 y ss. Para una visión crítica tanto de la argumentación como del resultado interpretativo que procuró el caso 'Simón'; BADENI (2005) p. 639 y ss.

17. Jensen, Carlos c/ Provincia de Mendoza (1922).

18. BACIGALUPO (1999) p. 75.

19. Adicionalmente a lo dicho en términos de seguridad jurídica, Mir Puig también ha sostenido que el principio de legalidad es una garantía política de que el ciudadano no podrá verse sometido a penas que no haya aprobado el pueblo a través del Poder Legislativo. MIR PUIG (2006) p. 106. En un sentido similar, ZAFFARONI (1987), tomo I, p. 140. De hecho, la posibilidad de conocimiento previo de las conductas que serán reprochadas con el poder punitivo del estado es uno de los requisitos mínimos del Rule of Law. GALLANT (2009) p. 15; ALLEN (1990) p. 814.

20. BACIGALUPO (1999) p. 75.

21. Posteriormente, el artículo 18 de la Constitución de la Nación Argentina establece una serie de garantías procesales como la inviolabilidad del domicilio, la garantía del juez natural de la causa, la 
titucional histórico de 1853-1860 fue complementado por la reforma del año 1994, que introdujo el artículo 75, inciso 22, el cual asignó jerarquía constitucional a diversos tratados internacionales de derechos humanos que recogen el principio de legalidad penal $^{22}$. De manera tal que este principio no solo está incorporado en disposiciones constitucionales strictu sensu, sino que su margen de protección está complementado y maximizado por el llamado 'bloque de constitucionalidad' ${ }^{23}$.

Ahora bien, una aplicación de las disposiciones jurídico-penales que reduzca el principio de legalidad a la interpretación literal de un texto o disposición normati$\mathrm{va}^{24}$ se enfrenta a dos serios problemas: (i) las lagunas estáticas, que son el producto de la falta de univocidad del lenguaje jurídico, lo cual se manifiesta paradigmática, aunque no solamente, a través de los llamados conceptos jurídicos indeterminados ${ }^{25}$. (ii) Lagunas dinámicas, las cuales se presentan ante la aplicación concreta de una disposición jurídico-penal que resultaría problemática de acoplar con el bloque de constitucionalidad; o bien lagunas que nacen con el devenir del tiempo - p. e., un concepto que incorpora el lenguaje del derecho quizá era unívoco en un tiempo, pero con el paso de los años está sujeto a ambigüedades o padece de cierta vaguedad $-{ }^{26}$.

inviolabilidad de la correspondencia y la prohibición de establecer penas de muerte por crímenes políticos. Junto con lo anterior, Zaffaroni plantea que el principio de legalidad también se encuentra recogido en el artículo $1^{\circ}$-que establece la forma republicana de gobierno- y el artículo $19^{\circ}$ de la Constitución de la Nación Argentina - el cual dispone que "Las acciones privadas de los hombres que de ningún modo ofendan al orden y a la moral pública, ni perjudiquen a un tercero, están sólo reservadas a Dios, y exentas de la autoridad de los magistrados"-. ZAFFARONI (1987) tomo I, p. 132. En un sentido similar, GALLANT (2009) p. 18.

22. EDWARDS (1996) pp. 78-79. Más específicamente, las disposiciones jurídicas internacionales a las cuales se les ha atribuido rango constitucional que hacen referencia al principio de legalidad penal son: a) Declaración Universal de Derechos Humanos, art. 11º ap. 2; Convención Americana sobre Derechos Humanos, art. $9^{\circ}$; Pacto Internacional de Derechos Civiles y Políticos, art. $15^{\circ}$, ap. 1.

23. FUENTES CONTRERAS (2019) p. 32.

24. DONNA (1996) p. 12. Durante este trabajo emplearemos 'disposiciones jurídicas' como sinónimo de 'formulaciones normativas', por lo que seguiremos en este punto a Alonso, aunque como lo indica el citado autor, bien podría considerarse que tales formulaciones son el género, del cual se desprende una de sus especies: las disposiciones juridicas. Con todo, aquí resulta tolerable realizar tal asilimilación terminológica, puesto que no hablaremos sino de formulaciones normativas que se expresan a traves de disposiciones jurídicas, sin hacer referencia a otros ámbitos normativos $-v . g r$., moral o religión-. ALONSO (2010) pp. 13-14.

25. LOMBARDI VALLAURI (1981) pp. 32-33. De hecho, la proliferación de los conceptos jurídicos indeterminados ha llegado a tal punto que eso ya no sosprende a ningún jurista. BACIGALUPO (2005) p. 326.

26. LOMBARDI VALLAURI (1981) pp. 36-39. 
Así, parece que la aplicación del derecho penal ha de conciliar dos extremos; por un lado, la prohibición de una aplicación analógica de las normas jurídicas y, por el otro, un respeto celoso al principio de legalidad. Lo último resulta ser una cuestión especialmente delicada porque, al fin y al cabo, el advenimiento de regímenes totalitaristas como el nazismo se afincó en una dogmática penal fundada en dos puntos estrechamente interrelacionados: i) la eliminación de la prohibición de aplicación analógica de las normas penales y (ii) la atribución de culpabilidad al autor de un pretenso delito sobre la base de una referencia a conductas atípicas ${ }^{27}$.

Situados en este contexto, lo que está en juego en el caso de la interpretación dinámica o evolutiva de los tipos penales es, a la vez, un problema de interpretación de disposiciones constitucionales. En concreto, ¿una interpretación dinámica de un tipo penal es una vulneración al principio de legalidad reconocido en el artículo 18 de la CN? La diferenciación o compartimentalización de las técnicas interpretativas penales resulta, a la postre, simplemente inviable en un Estado Constitucional de Derecho. En otras palabras, los efectos verticales de la constitucionalización del Derecho suponen el reto de armonizar la interpretación de normas penales con la interpretación constitucional.

En efecto, la interpretación dinámica no es más que una manifestación de la aplicación analógica del derecho. Ahora, si tal clase de analogías están proscritas por la dogmática penal debido al principio de legalidad, pues cabría entonces plantearnos si estamos en un campo gobernado por 'la mano muerta del pasado'. Esta metáfora refiere a que la generación actual no es la que decide cómo o de qué manera concretaremos las disposiciones constitucionales, sino que estamos frente al deber de hacer cumplir lo que decidieron quienes aprobaron y ratificaron aquellas disposiciones constitucionales que actualmente tenemos que interpretar para hacer frente a los retos de la hora presente ${ }^{28}$.

La metáfora de 'la mano muerta del pasado' reviste un notable atractivo para el derecho penal y, muy especialmente, en lo que respecta a determinados aspectos del principio de legalidad ${ }^{29}$. Porque esto implicaría que los jueces han de ser fieles al Derecho, no importa el paso del tiempo y, por tanto, solo deben limitarse a aplicar tipos penales existentes. No solo no cabe lugar a ninguna creación pretoriana de delitos, sino que tampoco hay espacio para alguna clase de aplicación analógica de las dis-

27. ZAFFARONI (1987) tomo II, p. 369; NINO (1980) p. 42. En un sentido similar, dejar de lado el mandato de determinación que implica el principio de legalidad es uno de los elementos centrales o estructurales del 'derecho penal del enemigo'. CANCIO MELIÁ (2003) pp. 88-89.

28. Para una visión crítica sobre lo que implica el problema de la 'mano muerta del pasado', RUBENFELD (1997) p. 1087 y ss. Para una defensa de la tesis de que todo Derecho, en cierto sentido, supone una imposición del pasado sobre el presente, ROSLER (2019) p. 73.

29. ROSLER (2019) p. 73. 
posiciones penales. La noción de estar gobernados por la 'mano muerta del pasado' entonces parece estar alineada con el principio de legalidad, uno de los principios constitucionales más fundamentales o básicos del derecho penal para salvaguardar la libertad frente a la potestad punitiva del Estado.

No obstante, cabría plantearse si esa 'mano muerta del pasado' no deriva acaso en una aplicación o concepción tan estricta del principio de legalidad que imposibilitaría la eficacia de no pocas normas penales; especialmente, por ejemplo, aquellas disposiciones jurídicas que describen supuestos de hecho que mutan con el avance de las tecnologías - p. e., delitos vinculados con el grooming, cuya materialización va transformándose al ritmo de los avances tecnológicos o aquellos en que el objeto sujeto a regulación jurídica evoluciona constantemente como, por ejemplo, los delitos vinculados con el tráfico de estupefacientes o lavado de activos-. En tales casos, ¿no se advierte una tensión entre la eficacia de las normas penales a lo largo del tiempo y una aplicación estricta del principio de legalidad? ${ }^{30}$

\section{La prohibición de analogía en el derecho penal: implicaciones para la inter- pretación extensiva y la interpretación dinámica}

El derecho penal, en cualquiera de sus ramas, constituye un sistema riguroso y cerrado, formado por ilicitudes discontinuas, el cual no admite, por la clase de objetos jurídicos de los que se ocupa, ningún tipo de integración, extensión o analogía tendiente a completar los elementos esenciales de las figuras creadas por la ley ${ }^{31}$. La proscripción de analogía no es más que una de las cuatro prohibiciones que se desprenden del principio de legalidad que recoge el art. 18 de la Constitución de la Nación Argentina, tal como se ha mencionado anteriormente ${ }^{32}$.

La ciencia del derecho penal establecía que la prohibición de analogía en materia penal no ofrecía dificultades para su realización práctica, en tanto y en cuanto los tipos penales contenían supuestos de hecho referidos a un número exacto de $\operatorname{casos}^{33}$. Así se creía que se lograba la función garantizadora del derecho penal. Los albores del derecho penal moderno, en efecto, se esmeraban por sostener que la seguridad del ciudadano frente al poder punitivo del estado consistía en que el juez no podía hacer

30. Otros autores se han ocupado de examinar las implicancias de las vinculaciones entre el principio constitucional de legalidad en materia penal y el derecho internacional humanitario, especialmente aquel de origen consuetudinario. YACOBUCCI (2002) pp. 264-268.

31. Rolfo, Domingo Americo S/ Infley 17.250 (1979).

32. Más específicamente: 1) prohibición de cláusulas generales ; 2) prohibición de aplicación analógica; 3) prohibición de aplicación retroactiva; 4) prohibición de fundamentación de la sentencia condenatoria en derecho que no provenga de la ley en sentido formal. Supra 1.

33. BACIGALUPO (1999) p. 77. 
valoración alguna sobre el derecho que había de aplicar ${ }^{34}$. De esta manera, el respeto a la ley asumía una dirección formalista basada en la veneración por su estricta formulación lingüística; esto es, se exaltaba la literalidad de las disposiciones juridicas $y$, en cambio, no resultaba significativo el valor material que incorporase cada uno de los enunciados jurídicos ${ }^{35}$.

El agotamiento de un paradigma o modelo formalista ha puesto de relieve a la dimensión material del derecho, lo cual en el principio de legalidad penal implica un reto a la comprensión del subprincipio de taxatividad o mandato de determinación. Esto último supone un doble aspecto. Por un lado, el principio de legalidad penal se dirige al poder legislativo a través de la prescripción de una exigencia de una lex certa y, por el otro, se dirige al juez, al prohibirle la aplicación analógica de esa lex certa e imponiendo, en consecuencia, la obligación ineludible de ceñirse a la lex stricta ${ }^{36}$.

Situados en este contexto se puede apreciar que la interpretación extensiva, en efecto, se distingue del problema de la aplicación analógica de la ley penal ${ }^{37}$. La primera se trata de un método interpretativo que no se suele problematizar en términos de una aplicación analógica que vulnere el principio de legalidad. Ahora bien, esto subraya la importancia de distinguir entre una interpretación analógica y otra de tipo extensiva, ya que la segunda no sería problemática, mientras que la analogía sería inadmisible en términos de garantías constitucionales del derecho penal. Porque, una vez abandonada la otrora rígida concepción formalista y casuística, parecería que resulta difícil afirmar que las disposiciones jurídico-penales establecen un número cerrado y definitivo de casos $^{38}$.

De esta manera, la interpretación extensiva consistiría en establecer el máximo posible de casos que se desprenden de un tipo penal, pero siempre dentro del 'piso' semántico sobre las que se apoyan las formulaciones normativas, porque de lo contrario no sería interpretación en ningún sentido admisible ${ }^{39}$. Aún más, la jurisprudencia de la CSJN se ha ocupado de enfatizar que la interpretación de normas penales supone identificar la extensión o amplitud de los casos previstos por el legislador.

33. BACIGALUPO (1999) p. 77.

34. YACOBUCCI (2002) p. 241. En efecto, Beccaria planteaba que: "Nemmeno l'autorità d'interpetrare le leggi penali può risedere presso i giudici criminali per la stessa ragione che non sono legislator". BECCARIA (2017) [1764], cap. 4, "Interpetrazione delle leggi”.

35. YACOBUCCI (2002) p. 242.

36. YACOBUCCI (2002) pp. 256-257; SILVA SÁNCHEZ (1992) p. 254; MIR PUIG (2006) p. 107; MIR PUIG (1994) p. 127; ROXIN (1997) p. 170.

37. JIMÉNEZ DE ASÚA (1958) p. 122.

38. BACIGALUPO (1999) p. 77. En un sentido similar, JESCHECK (2002) p. 137.

39. Simón, Julio Héctor y otros s/ privación ilegítima de la libertad (2005), voto del Dr. Zaffaroni, consid. $n^{\circ}$ 24. En un sentido similar, ZAMBRANO (2009a) p. 79. 
Se podría, pues, afirmar que la frontera entre el principio de taxatividad o mandato de determinación, fuera de un modelo de aplicación del derecho de corte formalista, exige precisar el rango de casos que están contenidos en los tipos penales, ya que solo dentro de ese rango se estaría aplicando tales normas penales de conformidad al principio constitucional de legalidad. Con otras palabras, solo estamos interpretando - y no creando- el derecho penal si estamos "atados" en alguna medida por el lenguaje por el cual se expresan las disposiciones jurídicas.

No obstante, esa pretensión de identificar la extensión de los casos previstos por la ley no resulta una tarea sencilla porque para ello no basta con realizar una interpretación literal. En efecto, se torna imperioso determinar la 'inteligencia exacta de la ley' cuando su letra ha expresado solo de manera incompleta o, más aún: incorrecta, la voluntad legislativa ${ }^{40}$. De hecho, la delimitación de la cantidad de casos previstos por la ley tampoco cabe realizarse a través de una mera interpretación literal de las disposiciones jurídico-penales, ya que ello podría derivar en no pocos absurdos que resultarían inaceptables para el legislador ${ }^{41}$. Por ejemplo, el caso de un conductor que, a los lejos advierte la presencia policial y que luego decide ceder el manejo del auto a su compañero. El primer conductor rechaza un examen de alcoholemia bajo el argumento de que no estaba incumpliendo la ley, ya que esta disponía que solo a "toda persona que estuviera manejando o intentando manejar" se puede requerir una prueba de alcoholemia ${ }^{42}$.

Ahora bien, si no cabe lugar para una mera - por favor, téngase muy presente el destacado en 'mera'- interpretación literal, ¿cuál es la noción que regula los límites de aquello que está proscrito por la prohibición de analogía? La respuesta que propone la CSJN es conciliar la prohibición de analogía con una dimensión finalista o teleológica inherente a toda interpretación jurídica, incluso en el supuesto de disposiciones jurídico-penales ${ }^{43}$. De esta manera, la CSJN entendió que no se advertía un caso de analogía en el supuesto en que un acusado había perturbado la tenencia de un inmueble alquilado por la víctima, a pesar de que el tipo penal solo describía como elemento típico del delito de usurpación a quien turbase la posesión de un bien inmueble.

40. Relojerías Fernández S.C.A. s/ apelación clausura (1997a), consid. nº 6. En un sentido similar, Silva Sánchez plantea que el quid de la interpretación de la ley penal no es establecer la verborum ratio, sino la ratio legis de la formulación normativa en cuestión. SILVA SÁNCHEZ (2006) p. 382.

41. Lambruschi, Pedro Jorge s/ ley 23.771 (1997b), consid. n 6. Para una explicación sobre el rechazo de la interpretación literal por su incapacidad para evitar resultados absurdos, GOLDSWORTHY (1994) p. 158 y ss; GOLDSWORTHY (2011) p. 14; GOLDSWORTHY (2005) p. 498 y ss.

42. Para este y otros ejemplos más en lo que efectivamente ha incurrido la interpretación literal en el sistema jurídico del commonwealth, GOLDSWORTHY (2005) pp. 496-497.

43. Godoy, Roberto Carlos s/ ley 11.683 (1993), consid. $n^{\circ} 7$. 
El caso reseñado permite apreciar que una interpretación literal hubiera devenido en la calificación de la acción juzgada como atípica, pero la incorporación del elemento finalista permite extender el supuesto de hecho a casos no expresamente previstos por la disposición-jurídico penal, sin que ello implique cercenar el principio de legalidad a través de una indebida aplicación analógica del delito de usurpación ${ }^{44}$. Con todo, tal como aclara la CSJN, esta incorporación de elementos finalistas o teleológicos se ha de mantener dentro de criterios restrictivos ${ }^{45}$. Parafraseando a Bobbio, se podría afirmar que este razonamiento no es aceptable o razonable porque es justo, sino que es justo porque es razonable ${ }^{46}$.

Ahora bien, el punto que parece subrayar la CSJN es que la operación por la cual se extienden los casos penales más allá de la letra de la ley debe realizarse con sumo cuidado y, me permito agregar, procurando conciliar la eficacia de la ley penal con el resto de las garantías constitucionales y con la sistemática misma del derecho penal. Dicho de otra manera, lo que la CSJN sugiere es que la 'búsqueda de la inteligencia exacta de la ley' no debe realizarse a la ligera al punto de cercenar otros derechos fundamentales de la persona frente al ejercicio de la potestad punitiva en manos del estado.

\section{La interpretación dinámica del principio de legalidad: entre la adaptabilidad a las circunstancias y la fidelidad a lo dispuesto por la ley penal}

\subsection{Distinciones preliminares: la interpretación evolutiva o dinámica y la inter- pretación viviente}

El principio de legalidad suele presentarse bajo tensión en lo que respecta a la aplicación dinámica de los tipos penales ${ }^{47}$. Por ejemplo, en el momento en que eclosionó el tráfico de las comunicaciones electrónicas, pero cuando el texto del Código Penal todavía se limitaba a penalizar solo a quien accediera indebidamente a las comunicaciones y papeles privados de una persona, no faltó quien declarase que el apoderamiento ilegitimo de correos electrónicos resultaba ser una conducta atípica ${ }^{48}$. El

44. Sobre este punto volveremos más adelante, en el apartado 5 de este mismo trabajo.

45. Godoy, Roberto Carlos s/ ley 11.683 (1993), consid. $n^{\circ} 7$.

46. BOBBIO (2004) p. 259.

47. Jakobs plantea que es posible reconciliar la continuidad de la evolución conceptual con la aplicación no analógica de la ley penal. La propuesta del citado autor, en efecto, trata de erradicar ciertos resultados absurdos y, por ende, valoraciones arbitrarias a las que se arribaría si se rechazara necesariamente toda posibilidad de evoluciuón conceptual. JAKOBS (1997) p. 105. Con todo, resulta llamativo que el citado autor no precisa o ejemplifica a qué se refiere por medio de la expresión 'resultados absurdos'.

48. Lanata, Jorge S/ desestimación (1999a). 
tribunal que resolvió la apelación en tal caso decidió que el avance tecnológico - ya en el año 1999- parecía haber dejado en una zona de "obsolescencia al bien jurídico que tutela el Capítulo III, Título V del Código Penal, en especial a los artículos que se ocupan de la protección de los papeles privados y la correspondencia"49.

El caso mencionado anteriormente, ¿se trata de un ejemplo de interpretación analógica o una interpretación dinámica que se orienta directamente a concretar el ius puniendi frente a los cambios en las circunstancias de aplicación del delito de violación de la correspondencia? La respuesta, al modo de ver de quien escribe la presente investigación, exige precisar el concepto de interpretación dinámica o evolutiva del derecho. De hecho, se trata de una cuestión relevante porque existe cierta imprecisión conceptual sobre el alcance de lo que significa una interpretación dinámica o evolutiva de las normas.

Frente a la anterior dificultad cabe precisar que la noción de interpretación dinámica o evolutiva en materia constitucional podría resultar también admisible en el campo de la dogmática y práctica del derecho penal y, en cambio, la interpretación viviente sería altamente problemática ${ }^{50}$. En efecto, la primera refiere a que la constitución ha de complementar a las formulaciones normativas, tradición y prácticas con las aspiraciones, valores, ideales y realidades actuales, pero sin negar la centralidad de las disposiciones jurídicas ${ }^{51}$. De esta manera, no estamos frente a un dilema entre aplicar un texto normativo o las convenciones semánticas a las que este refiere, sino en un contexto en que se articulan valores y aspiraciones actuales con el fin de clarificar el significado de una disposición jurídica.

Se trata de lograr atender a las creencias sociales predominantes, pero también se pretende rechazar el extremo de que estas sustituyan a las disposiciones jurídicas como limitación de la actuación gubernamental ${ }^{52}$. Así, la incorporación de los empleados de empresas de telefonía celular al campo semántico de los agravantes del

49. Lanata, Jorge S/ desestimación (1999b).

50. SAGÜÉS (2016) p. 38. Otros autores, en cambio, han utilizado categorizaciones similares, solo que a lo que Sagüés designa como 'interpretación viviente' Moore, por ejemplo, le llama 'interpretación viviente sustitutiva', MOORE (1989) p. 115. La distinción parece ser terminológica y no propiamente conceptual, pero vale la pena realizarla porque lo que Sagüés distingue como interpretación dinámica o evolutiva no pocas veces se engloba dentro de lo que se ha llamado 'constitucionalismo viviente' en la tradición norteamericana, tanto estadounidense como canadiense. Para un desarrollo de esta categorización: LAISE (2019) p. 228. Con todo, un punto que podría justificar a la terminología de Sagüés es que lo opuesto a una constitución viviente sería una constitución muerta, lo cual no podría ser apoyado, salvo por un necrófilo, tal como Rehnquist insinúa sarcásticamente. REHNQUIST (1976) p. 693.

51. En un sentido similar, GREY (1974) p. 709; KAVANAGH (2003) p. 87; LESSIG (1994) pp. 396397; WALUCHOW (2005) p. 222.

52. SAGÜÉS (2016) p. 38. 
delito de violación de correspondencia por la calidad especial de los sujetos activos no implicaría una sustitución de la formulación normativa - Art. 154 del Código Penal-, sino tan solo un complemento. En tal ejemplo no se ha procedido en modo alguno a reemplazar la citada disposición jurídica por una que se estima como más justa, basada en una creencia generalizada o compartida.

La interpretación dinámica tan solo estaría adicionando un caso al supuesto de hecho para que la disposición jurídica no se vuelva mayor o principalmente obsoleta en virtud del paso del tiempo ${ }^{53}$. Porque, en efecto, las comunicaciones privadas no se canalizan sino excepcionalmente a través de medios postales o telegráficos. Dicho de otra manera, hoy parece ser que las comunicaciones postales son la excepción y no la regla; salvo en lo que respecta a notificaciones fehacientes que se cursan en el marco de procesos extrajudiciales o en lo que incumbe al envío de paquetería. En consecuencia, limitar el supuesto de hecho al caso expresamente previsto en la formulación normativa implicaría aniquilar una parte sustancial de la pretensión normativa de esa disposición jurídica.

La interpretación viviente, como la ha nombrado Sagüés, o más precisamente: interpretación evolutiva sustitutiva, presenta otras dificultades que, si bien son muy apremiantes para el derecho constitucional, resultan de suma relevancia para la vigencia material de la legalidad penal. En efecto, la interpretación viviente conllevaría la entera sustitución del texto normativo por las aspiraciones y valores morales contemporáneos, tal como lo ha planteado Moore ${ }^{54}$. Esto supondría la trágica consecuencia de que ya no sería la constitución la ley suprema del Estado, sino que estaríamos gobernados, en último término, por las aspiraciones y valores morales a los que remiten las disposiciones constitucionales ${ }^{55}$.

Así, una interpretación viviente haría colapsar a la noción misma de supremacía constitucional, de igual modo se vería cercenado el núcleo mínimo del principio de legalidad penal. El propósito mismo de plantear una ley escrita, previa a la comisión de un delito, que permita a los ciudadanos ajustar su propia conducta en un determinado sentido, se vería enteramente comprometido si las aspiraciones y valores morales fueran las que prevalecen necesariamente frente a lo establecido en disposiciones jurídico-penales preexistentes. Se podría, en efecto, afirmar que ya no sería la ley penal la que dispone una sanción a determinadas conductas, sino la voluntad o el sentir popular. Si así fuera estaríamos demasiado cerca de que la interpretación del contenido de la costumbre sería la que fijaría los tipos penales o sus respectivas consecuencias jurídicas, sin ninguna clase de ley formal.

53. CREUS (1999). En un sentido similar, BADENI (2006) Tomo I, pp. 116-117.

54. MOORE (1989) p. 115.

55. LAISE (2019) p. 229. 
Si lo último fuera la regla general, estaríamos negando que el propio sistema jurídico, pero más especialmente el derecho penal sustantivo, resulte capaz de ejercer autoridad sobre sus intérpretes actuales o, lo que es igual, que las generaciones anteriores no pueden constreñir de ningún modo a las conductas de las posteriores ${ }^{56}$. Si esto realmente fuera así, el ius puniendi no se derivaría de disposiciones jurídicas que se dictan de acuerdo con los procedimientos legislativos establecidos al efecto, sino el pueblo mismo sería quien especificaría qué conductas resultan delictivas y cuáles no, sin mediación alguna de las instituciones que establecen el derecho positivo que rige en el Estado ${ }^{57}$.

La aplicación de penas se realizaría por medio de una remisión pura y directa a difusos estándares morales. Estaríamos, pues, en un contexto en que el derecho penal ya no solo estaría conectado excesivamente a la moral, lo cual sería problemático para la legitimación misma del derecho penal ${ }^{58}$. Más aún, la interpretación viviente disolvería por completo al ejercicio del poder punitivo en el torrente de la moral social. Esto no resulta un mero supuesto hipotético, sino que el nervio mismo de las condenas que imponía el derecho penal de la era nazi se afincaba en una reinterpretación de las disposiciones jurídico-penales, lo que se basaba en sus actividades y actitudes morales de los jueces como miembros del volk ${ }^{59}$.

\subsection{El problema de la caracterización metodológica de la interpretación diná- mica de leyes penales}

Una vez que se ha rechazado a la interpretación viviente, cabría preguntarse cómo interpretar una norma penal de acuerdo con la metodología que propone la interpretación dinámica complementaria. Esto es una cuestión retadora porque es frecuente que las distintas teorías de la interpretación jurídica defiendan tal o cual método interpretativo sobre la base de un cierto concepto de autoridad del Derecho. Lo dicho anteriormente resulta entendible porque toda práctica interpretativa asume, implícita o explícitamente, alguna causa que explica y justifica porque el intérprete ha de dejarse guiar u orientar por una determinada formulación normativa ${ }^{60}$.

\section{ROSLER (2018) p. 20.}

57. A mi modo de ver, cuando el artículo $22^{\circ}$ de la Constitución de la Nación Argentina establece que "El pueblo no delibera ni gobierna, sino por medio de sus representantes y autoridades creadas por esta constitución” se estaría haciendo referencia, entre otras cosas, a la necesaria aplicación de sanciones coactivas a partir de una decisión judicial, la cual se ha de basar en formulaciones normativas preexistentes.

58. Se ha planteado que el derecho penal tiene por función no castigar cualquier clase de inmoralidad, sino aquellas que afecten significativamente a bienes jurídicos, ZAFFARONI (1987) tomo I, p. 36.

59. MÜLLER (1987) p. 103.

60. MCCONNELL (1997) p. 1128. 
Sin embargo, ¿cuál es la razón que justifica la autoridad de formulaciones normativas, muy especialmente, de aquellas que reconocen derechos fundamentales? Pues los presupuestos morales y políticos que son protegidos y reconocidos por la disposición jurídica que se ha de interpretar ${ }^{61}$. En el caso del principio de legalidad cabe preguntarnos cuáles son tales contenidos morales y políticos que son tutelados por el ordenamiento jurídico. A lo que cabría responder que de lo que se trata, en primer lugar, es de garantizar a cada habitante de la Nación que no será perseguido por cualquier clase de descripción de conductas delictivas, sino solo en tanto y en cuanto exista una ley previa directamente orientada a proteger un bien jurídico. Y, en el plano político, se trata de asegurar que la descripción de los supuestos de hechos contenidos en tipos penales y sus correlativas penas solo pueden ser establecidas por una ley formal del Congreso de la Nación ${ }^{62}$.

Ahora bien, lo dicho hasta el momento nos indica una serie de razones que podrían justificar a la práctica interpretativa, pero nada nos dice sobre cómo operacionalizarla; menos aún cómo llevar adelante una interpretación evolutiva de normas jurídico-penales. Dicho de otro modo, la cuestión sobre la autoridad del derecho nos esclarece por qué hemos de optar por tal o cual método interpretativo, pero nada nos insinúa sobre cómo llevarlo a cabo ${ }^{63}$. Más aún, las defensas de los métodos interpretativos se suelen concentrar unilateralmente en las ventajas o superioridades de un método, pero sin proporcionar una determinada caracterización metodológica ${ }^{64}$.

De esta manera, persiste la pregunta que atañe a este trabajo, la cual suele ser generalmente omitida por los juristas - ya sea por dogmáticos, teóricos o filósofos del derecho- que podríamos sintetizar del siguiente modo: ¿cómo interpretar normas jurídicas según un método dinámico o evolutivo ${ }^{65}$ ? Y, más en concreto, ¿cómo interpretar dinámicamente normas jurídico-penales? En los próximos subapartados se procurará brindar una respuesta a la antedicha pregunta.

\section{Algunas precisiones metodológicas: la cuestión sobre cómo interpretar diná- micamente a las normas penales}

Las directivas que a continuación se presentan se desglosan con el fin de presentarlas de un modo sistemático y didáctico. Sin embargo, cada una de ellas resultan ser secuencias o pasos metodológicos encadenados unos con otros para con ello formar un

61. MCCONNELL (1997) p. 1128.

62. JESCHECK (2002) p. 137. Opinión Consultiva OC-6/86, parr. 22 y ss.

63. LAISE (2017) p. 247.

64. MOORE (2000) p. 298.

65. Entre las excepciones cabría mencionar: LAISE (2018) y LAISE (2019). 
andamiaje que ha de desplegarse armónicamente. Resulta conveniente no desconectar a estas directivas de la totalidad a la que pertenecen porque se podría desvirtuar su sentido. Por ejemplo, la identificación de tendencias jurisprudenciales y doctrinarias se ve limitada por el horizonte de sentido de la práctica interpretativa en materia penal. Se trata, en efecto, de cuatro pilares íntimamente enlazados; de hecho, separar a uno del otro implicaría desnaturalizar la propuesta que a continuación se presentará.

\subsection{Primera directiva interpretativa: reconocer el horizonte de sentido o finali- dad de la práctica interpretativa del derecho penal}

Esta directiva interpretativa pretende subrayar o enfatizar que la práctica interpretativa -en general- y la práctica interpretativa en materia penal - en particular - se dirigen a desarrollar ${ }^{66} \mathrm{o}$, como dice la dogmática constitucionalista alemana, a concretar $^{67}$ las garantías constitucionales que configuran al derecho penal. Y, en lo que respecta a este trabajo, lo más relevante consiste en comprender que el principio de legalidad ni es la 'carta magna del delincuente', como sugería provocativamente Von Liszt $^{68}$; como tampoco ese principio posee un sentido formal que depende meramente del aseguramiento de la eficacia de las pretensiones punitivas del Estado ${ }^{69}$. El principio de legalidad, en efecto, se dirige a alcanzar eficacia en la lucha contra la criminalidad, pero - a la vez- pone en el centro a la protección de la persona humana, con el fin de evitar que esta se halle sujeta a los vaivenes de la política criminal y/o de la aplicación arbitraria de la ley penal ${ }^{70}$.

Ahora bien, el sentido global o general de la práctica interpretativa jurídico-penal consiste en articular una dosis de significativa eficacia del ius puniendi, pero siempre bajo el respeto a los derechos y garantías de las personas involucradas en el proceso penal; sea el caso de los acusados o de las víctimas. Con todo, persiste la necesidad de especificar el fin de la norma. Lo cual nos lleva a una pregunta fundamental, ¿los fines de una norma se reducen a lo que el legislador pretendió significar al momento de adoptar una disposición jurídico-penal? ¿O existe una cierta autonomía semántica por la que la formulación normativa posee un significado que no depende enteramente del legislador histórico? ${ }^{71}$

66. RABBI-BALDI CABANILLAS (2020) pp. 286 y ss.

67. HESSE (1992) p. 15. En un sentido similar, se ha planteado que los principios tienen la función de "transparentar las razones o motivos que justifican o pretenden justificar a los preceptos que mandan realizar una determinada conducta favorece a que el derecho logre los fines que se propone o persigue". ETCHEVERRY (2020) p. 24.

68. VON LISZT (1970) p. 80.

69. PERISTERIDOU (2015) p. 136.

70. PERISTERIDOU (2015) p. 137.

71. SILVA SÁNCHEZ (2006) p. 373; MOORE (2000) p. 2092. 
La respuesta a estos interrogantes consiste en que las formulaciones normativas tienen un significado que no está del todo sujeto a la voluntad del legislador histórico. Lo que nos plantea un problema adicional, ¿cómo se conoce la finalidad de las disposiciones jurídicas si esta trasciende a lo que el legislador pretendió significar? Al respecto, como plantea Silva Sánchez, cabe responder que la finalidad de la norma se interpreta a la luz de una cierta concepción de la racionalidad del derecho - en general-y del derecho penal - en particular $-{ }^{72}$.

Así, las finalidades que busca una particular disposición jurídica no son sino las consecuencias fácticas y normativas que se seguirían en caso de que se le atribuyese un determinado sentido a la disposición jurídica bajo interpretación. El punto consiste en "hallar el Derecho con la ayuda de modelos de orden, que no son comprensibles como mandatos, sino como encargos de actualización de un fin normativo, sobre todo de un fin normativo que puede estar previamente vinculado e incluido en un sinnúmero de otras referencias regulativas actuales"73.

Esto, a su vez, pone de relieve que la interpretación finalista ha de engarzarse con una lectura sistemática del ordenamiento jurídico. En efecto, ¿tales consecuencias normativas y fácticas son coherentes y consistentes con los fines globales de la práctica del derecho penal? A lo que cabría responder que la tarea de determinar el sentido finalista a una norma jurídico-penal no es posible sino a la luz de una particular teoría -en sentido amplio- ${ }^{74}$.

De hecho, la elucidación de los fines de una norma penal es una tarea racional, pero en tanto y en cuanto se apoye en un marco teórico determinado, lo cual implica asumir los postulados básicos de alguna clase de política criminal ${ }^{75}$. Por ejemplo, en la medida en que estemos frente a una política criminal que asume una teoría unitiva de la pena; es decir, una concepción de la pena que tanto apunta a la prevención general -en un plano general y abstracto- como, a la vez, a la resocialización del reo en lo que respecta a la aplicación concreta de las disposiciones jurídico-penales, el fin de la pena de delitos contra la administración pública podría ser la resocialización del condenado y, al tiempo, la disuasión general respecto a quienes podrían llegar a cometer tales crímenes ${ }^{76}$. En cambio, una visión centrada unilateralmente en la prevención general de esos delitos podría admitir el establecimiento legal de penas que superen

72. SILVA SÁNCHEZ (2006) p. 208; COTTA (1991) p. 10.

73. ESSER (1986) p. 46.

74. SILVA SÁNCHEZ (2006) p. 376.

75. SILVA SÁNCHEZ (2006) p. 376.

76. BACIGALUPO (1997) pp. 14-15. 
con creces al tiempo necesario para la resocialización del reo, siempre y cuando se advierta evidencia empírica que sustente tal decisión de política criminal ${ }^{77}$.

Eso nos lleva a que esa racionalidad del derecho penal asume necesariamente un punto de partida; esto es, un propósito fundamental que se encuentra sintéticamente condensado en el sentido que le hemos atribuido al principio de legalidad; esto es, conciliar la eficacia de la potestad punitiva con la protección de la persona humana implicada en el delito; ya sea en su calidad víctima o acusado ${ }^{78}$. En este orden de ideas no hay posibilidad alguna de asumir justificadamente un resultado de la interpretación finalista que sea inconsistente con el principio de legalidad. Sin embargo, esto no es suficiente en clave metodológica. La interpretación finalista tan solo provee de una hipótesis inicial que deberá someterse al escrutinio de una interpretación sistemática.

Ahora bien, aquella finalidad que le cabe atribuir una determinada norma ¿traerá mayor incertidumbre al sistema jurídico? ¿Resulta esto coherente y consistente con el sistema jurídico? ¿El resultado final colapsa o refuerza la distinción entre derecho y moral? Son estas las consideraciones básicas sobre la que se estructura la interpretación sistemática que ha de seguir a una interpretación finalista de la ley penal. Veamos.

\subsection{Segunda directiva interpretativa: reconocer a los actores institucionales en- cargados de materializar las aspiraciones incorporadas en la constitución}

Una vez establecido cómo se detectan las tendencias jurisprudenciales y doctrinarias resulta interesante señalar que, de acuerdo con los defensores de la interpretación evolutiva, los operadores jurídicos - especialmente los jueces que practican el control de constitucionalidad - no se limitan a seguir el cauce de la historia. Por el contrario, la práctica interpretativa ha de consagrar estándares o principios a los que las personas sujetas a esa constitución han de aspirar ${ }^{79}$. En otras palabras, la práctica interpretativa no sigue el curso de la historia, sino que ésta es modelada por la interpretación de los derechos fundamentales.

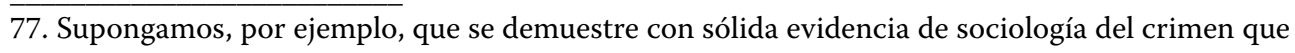
los delitos contra la administración pública se reducen en un 25\% (promedio) en los países de la región que establecieron la imprescriptibilidad de tales crimenes y, a su vez, penas comparables a la de delitos violentos como robo a mano armado u homicidio.

78. $\operatorname{ESSER}(1961)$ p. 34.

79. MILLER (1970) p. 240. 
Lo último plantea un interrogante de suma relevancia, ¿quién es el actor institucional encargado de consagrar tales aspiraciones? ¿Son los intérpretes judiciales o es el poder legislativo el que establece los contornos de los hechos delictivos y de las penas? La pregunta, en realidad, esconde una suerte de falso dilema. Es preciso aclarar que los jueces amplifican la voz de la comunidad ${ }^{80}$, lo cual se expresa a través de las leyes, por lo que no cabe que los jueces repliquen sus propios pareceres $\mathrm{u}$ opiniones a través de su labor jurisdiccional. La función judicial, en efecto, practica la interpretación jurídica para buscar concretar el significado de las disposiciones iusfundamentales en los casos sometidos a su jurisdicción ${ }^{81}$.

Siguiendo este orden de ideas, Miller advierte que la razón por la que la Constitución de los Estados Unidos de América ha durado tanto - el texto constitucional más antiguo entre aquellos que actualmente siguen vigentes - radica en la adaptación del tal documento normativo a los problemas de cada época que ha realizado la Corte Suprema $^{82}$. Aún más, la causa que explica la perdurabilidad del texto constitucional estadounidense consiste en que la Corte Suprema de Justicia opera de una manera cuasi religiosa. Con todo, se ha de aclarar que no me estoy refiriendo a cuestiones de índole confesional o dogmáticas en materia de creencias sobrenaturales. Se trata esto de una metáfora. Permítaseme explicarla.

El punto que se pretende ilustrar es que, si se asume que la constitución hace las veces del texto sagrado de la religión civil de un Estado ${ }^{8_{3}}$, pues entonces - prosigue Levinson con una buena dosis de ironía - cabe trazar una analogía entre el orden constitucional y la tradición religiosa cristiana: la constitución le habría confiado la llave del "reino de los cielos" a la Corte Suprema de Justicia ${ }^{84}$. En consecuencia, lo que ate la Corte Suprema a la constitución resultará parte de ella y lo que desate, pues, no lo será.

80. BRENNAN (1985) p. 434.

81. HESSE (1992) p. 15.

82. MILLER (1970) p. 243; MILLER (1962a) pp. 641-642.

83. GREY (1988) p. 223.

84. LEVINSON (2003) p. 124. Además, la metáfora religiosa, como Perry lo ha señalado, pretende remarcar que la interpretación constitucional se asemeja más a la interpretación de textos sagrados que a la interpretación literaria. Porque lo que está en juego es interpretar el significado de formulaciones normativas que tienen alguna clase de autoridad sobre cómo hemos de llevar adelante nuestras acciones y decisiones. No se trata meramente de dilucidar lo que pretendió significar un determinado autor de una obra, tal como se hace en la interpretación literaria. PERRY (1985) p. 562. Para una detallada explicación de las diferencias entre la interpretación de un texto sagrado y la de un texto constitucional, GREY (1984) pp. 15-17. 
La metáfora que propone Miller pretende significar que la constitución es un objeto de deferencia y adoración para el pueblo ${ }^{85}$ - tal como lo eran las tablas de ley mosaica para el pueblo judío-y, en la misma medida, los jueces que practican el control de constitucionalidad hacen las veces de predicadores de ese mensaje cuasi-divino expresado por el texto constitucional ${ }^{86}$. La hipérbole religiosa lo que subraya no es la deseabilidad de una aplicación del Derecho basada en argumentos confesionales, sino la centralidad del intérprete para que las aspiraciones y valores morales contenidos en las disposiciones jurídicas se concreticen a lo largo del devenir de la historia en un determinado pueblo.

Así, la concreción que se pretenda realizar del principio de legalidad penal en la práctica interpretativa no es un fin en sí mismo, sino un instrumento para proteger al ciudadano por medio de una aplicación democrática de disposiciones jurídico-penales; ya que tales formulaciones normativas fueron establecidas por los mecanismos y procedimientos institucionales establecidos a tal efecto. Y, además, se pretende limitar el poder punitivo del Estado, el cual solo ha de reprochar conductas que fueron establecidas con antelación, pero no de cualquier modo, sino a través de determinados procedimientos formales para la creación de normas generales y abstractas. De hecho, como lo plantea Hassemer, el derecho penal no es sino un tipo de control social formalizado, lo cual permite vigilarlo, criticarlo y, en su caso, corregirlo ${ }^{87}$.

Recapitulando, la metáfora religiosa que propone Miller no tiene ninguna clase de pretensión espiritual. Antes bien, el citado autor se ocupa de remarcar la importancia del rol institucional de los tribunales —en general-y de la Corte Suprema de Justicia de la Nación - en particular- como indicador de las líneas jurisprudenciales y doctrinarias que reflejan la evolución de los derechos. Aún más, ese tribunal ejerce el rol de guardián de la conciencia moral de la comunidad; esto es, la Corte sería capaz de articular el sentido último que anima a las disposiciones que integran la constitución y, por ende, incluso tiene el deber de trascender los consensos actualmente presentes en la sociedad ${ }^{88}$.

85. MILLER (1965) p. 391.

86. MILLER (1970) p. 236.

87. HASSEMER (1989) p. 118.

88. MILLER (1970) p. 236. 


\subsection{Tercera directiva interpretativa: identificar las tendencias jurisprudenciales y doctrinarias}

La interpretación evolutiva de disposiciones jurídico-penales, en efecto, requiere más de un análisis de tendencias que una rígida concepción de principios estáticos ${ }^{89}$. Esto supone que las prácticas interpretativas han de guiarse por el estudio de convergencias históricas sobre las explicaciones doctrinarias y jurisprudenciales acerca de lo que significan las disposiciones constitucionales que atañen al derecho penal, junto con la evaluación crítica del contexto en el que el poder punitivo se desarrolla y evoluciona ${ }^{90}$.

Así, las disposiciones jurídicas, muy especialmente aquellas que reconocen garantías constitucionales, no serían un documento estático sino, como lo ilustra gráficamente la jurisprudencia canadiense, un "árbol viviente capaz de crecer y expandirse dentro de sus límites naturales"91. Esto se explicaría en virtud de que el lenguaje constitucional, "no es un cristal transparente e inmutable, sino la piel de un pensamiento viviente que puede variar significativamente de color y contenido, de acuerdo con las circunstancias y la época en que es utilizado", tal como la planteaba Holmes ${ }^{92}$. Dicho en otras palabras, la interpretación evolutiva supone acomodar las disposiciones jurídicas a las circunstancias específicas de la hora presente.

De esta manera, las disposiciones jurídico-penales terminarían siendo un instrumento que se desarrolla y adapta a las nuevas circunstancias contemporáneas y a la mutación de las creencias normativas, siempre dentro de los contornos propios de su función institucional; esto es, limitar el campo de acción del gobierno y de los particulares $^{93}$. En efecto, la interpretación constitucional del principio legalidad se ha de ordenar directamente a concretizar los principios configuradores del propio derecho penal; esto es; el bien común político y el reconocimiento de la dignidad de la persona humana ${ }^{94}$.

Ahora, ¿cómo se detectan esas tendencias? Pues, en primer lugar, a través de una observación de la jurisprudencia de los órganos encargados de interpretar los derechos fundamentales implicados en la aplicación de normas penales. Más específicamente, se ha de procurar localizar e identificar un punto de arranque en algún

89. MILLER (1970) p. 235; MILLER (1962b) p. 890.

90. Esto se inspira en: MILLER (1970) p. 236.

91. Edwards v. Attorney General of Canada (1930) p. 136.

92. Towne v. Eisner, Collector of United States Internal Revenue for the Third District of the State of New York (1918) p. 425, voto en disidencia del justice Holmes [la traducción es del autor de este trabajo]. En un sentido similar, BRENNAN (1985) p. 438.

93. WALUCHOW (2007) p. 884.

94. YACOBUCCI (2002) pp. 175-228. 
momento de la historia reciente, junto con una delimitación de lo que ha venido ocurriendo en el presente, para así elaborar una extrapolación de lo que sucederá en el futuro ${ }^{95}$. Se trata, en efecto, de una reconstrucción de la aplicación que se ha venido haciendo de las normas penales para con ello inferir cuál es la solución más verosímil que se habrá de adoptar por la práctica jurídico-penal.

Estas tendencias no son sino las expectativas depositadas en un futuro, el cual se construye a partir de una herencia legada por el pasado reciente. Esto implica un tipo de práctica de la historiografía, basada en un concepto reflexivo de "historia", que pretende explicar, justificar y legitimar los resultados interpretativos a partir de un ensamblaje o articulación entre el futuro y el pasado para afrontar los retos de la hora presente ${ }^{96}$. Estas tendencias históricas se reconocen a través de la historia que vincula experiencias concretas y expectativas particulares ${ }^{97}$. Dicho de otra manera, casi parafraseando a Holmes, conocer la extensión de las disposiciones jurídicas supone un estudio concienzudo de la historia ${ }^{98}$.

Miller profundiza lo dicho anteriormente y subraya que este análisis de tendencias ha de realizarse atendiendo a la organización material del funcionamiento de las ramas del gobierno y a la vinculación de esto con la efectiva vigencia de los derechos fundamentales ${ }^{99}$. Así, el examen de las tendencias hace referencia, por un lado, a una serie de derechos individuales frente a los excesos en que pudiera incurrir el ejercicio del gobierno del Estado y, por el otro, designa un proceso de igualamiento de los individuos entre $\mathbf{s i ́}^{100}$. Es menester remarcar una conexión entre la evolución de los derechos de los individuos y la visión del gobierno de la hora presente, ya que de lo contrario se podría arribar a resultados paradójicos o contradictorios, como bien advierte Miller.

Siguiendo tal orden de ideas, por ejemplo, la tendencia actual parece ser partidaria de un gobierno que interviene cada vez más en la sociedad y en la economía para posibilitar que un mayor número de personas goce de mayores niveles de autonomía personal ${ }^{101}$. La expansión de la regulación estatal se explica a partir de un elevado nivel de expectativa de satisfacción en lo que respecta a elenco de derechos individuales. De hecho, pareciera ser un lugar común que aumenta el catálogo de derechos

95. MILLER (1962b) p. 891; MILLER (1970) p. 237.

96. MILLER (1970) p. 237; KOSELLECK (2010) p. 109. En efecto, aquí se asume un concepto de historiografía que comprende a la llamada 'historia reciente', para un mayor desarrollo: ARÓSTEGUI (2004) p. 19 y ss.

97. KOSELLECK (2004) p. 258.

98. HOLMES (1896) p. 469.

99. MILLER (1989) p. 588.

100. MILLER (1962b) p. 891.

101. MILLER (1962b) pp. 891-892. 
individuales a la par que se intensifica la intervención del gobierno para asegurar tales derechos ${ }^{102}$. Se podría, en efecto, plantear que el modelo gubernamental actual concentra su acción política en la protección de la sociedad frente a determinadas conductas normalizadas como peligrosas o dañinas para el aseguramiento de las libertades individuales ${ }^{103}$.

La proyección que Miller formuló hace ya un buen tiempo (1982), con relación a que no solo se expandirá, sino que se acelerará la concentración de poder en el órgano ejecutivo del gobierno, no ha perdido una pizca de actualidad ${ }^{104}$. En efecto, la proliferación de cláusulas generales en el campo penal confirmaría aquello que planteó Miller hace unas décadas en el plano específico del derecho constitucional ${ }^{105}$. La llamada 'expansión del derecho penal' no hace más que reforzar la tesis de que la actividad estatal no solo incrementa las penas bajo descripciones bastante genéricas de los tipos penales, sino que se refleja en el auge de un 'derecho penal de la puesta en riesgo', en el cual se disponen sanciones desproporcionadas a acciones que resultan previas a la concreta lesión de bienes jurídicos ${ }^{106}$.

Un punto sobre el que cabe hacer una consideración es que los jueces deben limitarse a lo que la comunidad habrá de aceptar ${ }^{107}$. Según Miller, los jueces generalmente identifican esos tópicos y actúan en consecuencia ${ }^{108}$. Aún más, el citado autor sugiere que los jueces orientan los resultados de su decisión practicando una fina sensibilidad sobre lo que interesa a la opinión pública, prescindiendo de brindar razones que justifican rigurosamente sus decisiones ${ }^{109}$. Solo los profesores, algunos de sus estudiantes y unos pocos abogados especializados se interesan por analizar detenidamente los argumentos utilizados por los jueces en sus decisiones ${ }^{110}$.

102. MILLER (1962b) p. 892; MILLER (1989) p. 592.

103. FOUCAULT (2006) p. 404. Para una visión crítica de esta tendencia que pretender erradicar riesgos a traves de la insistente formulación normátiva de delitos de peligro abstracto, HASSEMER (1989) p. 24.

104. MILLER (1982) p. 660; MILLER (1972) p. 77.

105. BACIGALUPO (1999) p. 63.

106. CANCIO MELIÁ (2003) p. 64. La proliferación de este derecho penal de la puesta en peligro ha implicado el auge correlativo de los llamados delitos instrumentales; esto es, delitos que se anticipan a la lesión e, incluso, en algunas ocasiones a la puesta misma en peligro de un bien jurídico. Para un estudio monográfico de los delitos instrumentales, CRUZ (2020) passim.

107. MILLER (1979) p. 501.

108. MILLER (1979) p. 501; MILLER (1965) p. 380.

109. MILLER (1979) p. 502; MILLER (1983) p. 484. Para un comentario que defiende una interpretación evolutiva de los derechos y, asimismo, sostiene que los jueces deben comprometerse a tomar decisiones orientadas a alcanzar ciertos resultados, GREY (1988) p. 236.

110. MILLER (1979) p. 502. 
Con todo, la voz de la doctrina también se ha de escuchar a través de la técnica de 'análisis de tendencias' que se ha descrito anteriormente. En efecto, hay un punto que cabe remarcar porque resulta de la máxima importancia. La doctrina funciona como una suerte de dique de contención que limita a los órganos del Estado para que el poder punitivo no avance cada vez más sobre las garantías constitucionales de los ciudadanos ${ }^{111}$. Se podría decir que la doctrina funciona como una suerte de 'conciencia crítica' de la práctica jurisprudencial.

De esta manera, las elaboraciones científico-jurídicas pretenden acotar el avance del ius puniendi a un punto que desestabilice el sistema penal; ya sea por demasiado punitivismo, ya sea por demasiado garantismo. Por ello, vistos desde un punto de vista global, los trabajos científicos que elaboran la dogmática penalista y la filosofía de la pena se dirigen a que la pretensión punitiva del Estado alcance un punto de equilibrio entre la protección social y las garantías constitucionales de los ciudadanos en materia penal ${ }^{12}$.

En síntesis, la tercera directiva metodológica de una interpretación dinámica prescribe el deber de examinar las tendencias jurisprudenciales y doctrinarias recientes. Estas se revelan a través de las decisiones que toman los jueces y de los argumentos que desarrolla la doctrina. Siendo más específicos, un análisis de tendencias conlleva un examen de las decisiones y opiniones pasadas para con ello inferir la dirección que habrán de adoptar las futuras. Se trata, pues, de tomar decisiones en el presente, sobre la base de experiencias pasadas, para así construir un futuro que colme las expectativas depositadas en él.

\subsection{Cuarta directiva interpretativa: encajar a la interpretación finalista dentro de la sistemática del derecho penal}

El límite interpretativo que supone la prohibición de la analogía, tal como plantea Jakobs, se ha de localizar en la cultura de la interpretación en que se lleva a cabo la tarea de aplicar una norma jurídico-penal ${ }^{113}$. Esto supone no tanto buscar el sentido esencial que tienen los conceptos, sino lo que estos pueden admitir que se les atribuya como unidad de sentido. Por ende, la determinación del significado de los conceptos que recoge el derecho penal no es una mera operación intelectual que se limita a desentrañar el contenido semántico de lo que significa, por ejemplo: 'arma', sino la búsqueda incesante de los sentidos que la comunidad acepta o tolera atribuir a cada uno de los conceptos por los cuales se expresan las disposiciones y normas jurídicopenales.

111. En un sentido similar, ZAFFARONI (1998) p. 245.

112. Esto se inspira en: NINO (1980) p. 236.

113. JAKOBS (1997) p. 103. 
Ahora bien, ¿cuáles son los límites en lo que respecta a los sentidos que se le puede atribuir a una disposición jurídico-penal? La pretensión de razonabilidad y, a la postre, la pretensión de exclusión de la arbitrariedad en el razonamiento aplicativo o interpretativo del Derecho ${ }^{114}$. La manera en que esta exclusión de la arbitrariedad podría presentarse de un modo positivo es mediante una pretensión de razonabilidad, lo cual supone aferrar o sujetar la ley penal a un esfuerzo sistemático. En efecto, de lo que se trata es de que se le atribuya un significado a las disposiciones jurídicas a partir de una operación que siga un procedimiento reglado generalizable ${ }^{115}$. La interpretación ha de ser generalizable sin perturbar a la estabilidad, armonía o unidad de sentido del sistema jurídico ${ }^{116}$. De hecho, aquí cabe tener presente que la función básica del derecho penal es la estabilización de las condiciones que posibilitan una convivencia pacífica ${ }^{117}$.

La concreción de tal sistematización supone asumir que son deseables, al menos desde un punto de vista lógico, la completitud, la consistencia y la independencia del sistema jurídico ${ }^{118}$. La pretensión sistematizadora, en efecto, lo que debe procurar es un resultado interpretativo que optimice lo mejor posible, en cuanto más se pueda, aquellas tres características ideales de los sistemas jurídicos mencionadas anteriormente. En concreto, una interpretación evolutiva o dinámica de una norma penal debe procurar armonizar estos tres objetivos: 1) colmar lagunas normativas y, por lo mismo, erradicar o disminuir las contradicciones normativas; 2) articular una respuesta coherente y armónica con la totalidad de las instituciones jurídico-penales; 3) posibilitar la distinción entre el orden jurídico y otros sistemas normativos $-p$. e., la moral o la religión-.

Un ejemplo quizá sea útil para ilustrar más gráficamente lo que se viene argumentando. Más específicamente, una interpretación dinámica del tipo penal en el caso de violación de correspondencia agravada por el sujeto activo - Art. 154 del Código

114. En un sentido similar, RAZ (2003) p. 13; ZAMBRANO (2009b) p. 149.

115. JAKOBS (1997) p. 104. En un sentido similar, JESCHECK (2002) p. 165.

116. La pretensión de sistematicidad del ordenamiento jurídico es, quizá, uno de los mayores aportes de la tradición positivista a la reflexión teórica de las últimas décadas. Ahora bien, el compromiso con la identificación de criterios lógico-formales para reconocer la unidad de sentido de sistema jurídico, al modo de ver con quien escribe este trabajo, más que incorrecto resultaría insuficiente. En un sentido similar, MONTORO BALLESTEROS (2001) pp. 308-309.

117. HASSEMER (1999) p. 19.

118. ALONSO (2010) p. 74. Cabe aclarar que la pretensión de sistematicidad del ordenamiento juridico no necesariamente ha de estar vinculada a la tradición positivista. MONTORO BALLESTEROS (2001) p. 308. 
Penal argentino ${ }^{119}$-, nos permitiría echar algo de luz sobre esas cuestiones. De esta manera cabría plantear las siguientes interrogantes, i) ¿se incrementaría la magnitud del problema de las lagunas en el supuesto que asimilemos a un empleado de una empresa de telefonía celular al caso de un agente de la empresa de correos? ii) ¿el nivel de coherencia del sistema jurídico-penal se incrementa o se debilita al equiparar a un empleado de telefonía con los dependientes mencionados expresamente entre los sujetos activos del agravante del delito de violación de correspondencia? iii) ¿Se difuminan los límites que posibilitan distinguir al derecho de otros sistemas u órdenes normativos al equiparar a ese empleado de telefonía celular con los que se desempeñan en empresas de correo postal?

Ahora bien, ya que: i) no se incrementa la magnitud del problema de las lagunas, ii) se robustece el nivel de coherencia del sistema jurídico, y iii) se mantiene la distinción entre derecho y moral, entonces podríamos afirmar que estamos frente a un caso de una interpretación evolutiva, incluso en sede penal, que no merecería ser conceptualizada como un caso de 'prohibición de analogía. En cambio, la reciente sentencia del Tribunal Supremo Federal de Brasil sobre 'noticias falsas' se nos presenta como un caso en que se advierte una respuesta negativa a lo que venimos planteando. Lo que interesa a los fines de este trabajo, es que en el mencionado caso un mismo tribunal -el Tribunal Supremo Federal de Brasil- se encuentra impulsando y controlando un proceso penal ${ }^{120}$, con base en una imputación del delito de 'injurias' a raíz de unas publicaciones que los magistrados consideraron ofensivas para su dignidad moral. Dicho de otra manera, el citado tribunal hace las veces de fiscal, juez de garantías y tribunal que emite la condena definitiva.

Resulta sencillo notar que esa resolución judicial posee muchas aristas cuestionables como, por ejemplo, si el máximo tribunal a nivel federal se aboca a resolver un caso, ¿cómo hará el Estado brasileño para asegurar el derecho a la doble instancia en materia penal que reconoce el artículo 8, inciso 2, apartado h) de la Convención Americana de Derechos Humanos? ¿Se podría afirmar que se han respetado las garantías procesales mínimas - en concreto: el derecho a un juez imparcial- si el mismo órgano jurisdiccional es el que impulsa el proceso, controla jurisdiccionalmente la investigación preliminar y, a la vez, se encarga de dictar la sentencia condenatoria con carácter definitivo ${ }^{121}$ ?

119. CÓDIGO PENAL (Argentina), Art. 154: “Será reprimido con prisión de UN (1) mes a CUATRO (4) años, el que por su oficio o profesión se apoderare de una carta, de un pliego, de un telegrama o de otra pieza de correspondencia o de un mensaje de correo electrónico".

120. Inquérito 4.781 Distrito Federal (2019).

121. Esto parece altamente problemático para la separación de la etapa instructoria o preliminar de la etapa de condenatoria en el marco de todo proceso penal, tal como se ha consolidado en el mundo occidental a partir del ejemplo del Código de Instrucción Criminal de 1808 de Francia. MONTERO AROCA (2016) p. 60. 
Sin desmerecer la relevancia de las anteriores preguntas, lo que nos interesa es que en el mencionado caso brasileño se interpreta dinámicamente de un modo sorprendente, no tanto - o, mejor dicho, no solo- la posibilidad subsumir a la difusión de 'noticias falsas' - fake news - en el delito de injurias, sino la curiosa aplicación de la disposición procedimental que se invoca para justificar que el propio tribunal instruya y juzgue el caso ${ }^{122}$. En efecto, lo más sorprendente de la mencionada sentencia brasileña es que las supuestas 'noticias falsas' no se transmitieron desde el recinto del tribunal, a pesar de que la norma procedimental solo autoriza al Tribunal Supremo Federal a iniciar una investigación en caso de delitos que se comentan dentro de sus instalaciones edilicias.

De esta manera, el magistrado brasileño que elaboró la sentencia que se comenta decidió aplicar esa norma procedimental, por el mero hecho de que las personas afectadas son los mismísimos jueces del Tribunal Supremo Federal ${ }^{123}$. Por ende, cabía asimilar hechos acaecidos fuera del tribunal al supuesto de hecho previsto en la citada formulación normativa de índole procesal. Entonces, cabe preguntarse: ¿la interpretación dinámica de la citada disposición procesal penal incurre en la prohibición de analogía?

La respuesta al anterior interrogante resulta contundentemente afirmativa, porque se podría sostener que no se cumple con ninguna de las tres exigencias de la directiva de interpretación sistemática. En efecto, i) se incrementa notablemente la indeterminación del contenido semántico de los supuestos de hecho en los que el Tribunal Supremo Federal está autorizado a iniciar un proceso penal; esto es, se aumenta el nivel de incertidumbre sobre el alcance de las competencias del citado tribunal. ii) Se amplifica el nivel de incoherencia del sistema jurídico, porque el Tribunal Supremo Federal podría instar acciones penales no solo ante delitos cometidos dentro de sus dependencias, sino en todo caso en que sus magistrados estén afectados o involucrados. iii) Se difuminan los límites que posibilitan distinguir al derecho de otros sistemas $u$ órdenes normativos, porque ya no queda claro si lo que habilita a la intervención del TSF es una supuesta ofensa a la dignidad moral de sus magistrados, o si lo que permite impulsar la faz de instrucción reposa en criterios objetivos descritos con meridiana claridad en el Reglamento Interno del TSF.

122. En efecto, el Tribunal Supremo Federal brasileño apela al artículo 43 del Reglamento Interno del citado tribunal, el cual establece que: "Ocorrendo infração à lei penal na sede ou dependência do Tribunal, o Presidente instaurará inquérito, se envolver autoridade ou pessoa sujeita à sua jurisdição, ou delegará esta atribuição a outro Ministro".

123. Inquérito 4.781 Distrito Federal (2019). 


\section{Balance crítico: ¿la 'mano muerta del pasado' realmente tiene autoridad sobre nosotros?}

El rechazo de la prohibición de analogía no implica que la interpretación de la ley penal ha de encapsular o 'fijar' definitivamente el significado de las disposiciones jurídico-penales en un determinado momento de la historia. Asimismo, la prohibición de analogía no necesariamente conlleva la negación de toda clase de razonamiento analógico en el marco de una práctica interpretativa penal. Solo una noción demasiado formalista e ingenua de la interpretación jurídica podría pensar que la aplicación de la ley sería capaz de prescindir completamente de consideraciones analógicas ${ }^{124}$. Porque, de lo contrario, estaríamos asumiendo una suerte de ultrarracionalidad del legislador; esto es, que no hubo caso alguno que no se le pudiera haber ocurrido al órgano legislativo al momento de elaborar las disposiciones jurídicas contenidas en el código penal.

El reto que más bien plantea la prohibición de analogía en materia penal es que la interpretación judicial no se confunda enteramente con la creación de formulaciones normativas, lo cual le está vedado a los jueces por el principio de legalidad penal. Se trata, en efecto, de asegurar la autoridad del Derecho creado por los órganos competentes, procurando desplegar un razonamiento jurídico que sea analógico, pero en un sentido metodológico que consiste en establecer diferencias y similitudes entre la formulación normativa y el caso concreto ${ }^{125}$. En ese preciso sentido de la analogía en el campo del derecho, tal como lo plantea Kaufmann, no es posible de escapar de una aplicación analógica de la ley, ni siquiera en materia penal ${ }^{126}$.

El punto que parece querer subrayar la prohibición de analogía no es, en efecto, una completa exclusión del razonamiento analógico en el campo penal, sino que se ha de evitar una modificación del derecho penal bajo el pretexto de su interpretación ${ }^{127}$. Porque esta última no es sino una actividad cognoscitiva y valorativa, pero inmediatamente dirigida a concretar tanto las finalidades como los medios que emplea el derecho penal para asegurar una convivencia ciudadana pacífica y ordenada por y a través del derecho. El desafío que supone el control de la interpretación judicial consiste en reconocer cuando a través de la práctica interpretativa se pretende incluir nuevos supuestos de hecho o consecuencias jurídicas de índole criminal o penal.

124. KAUFMANN (1976) p. 41.

125. KAUFMANN (2005) p. 408. En un sentido similar, JESCHECK (2002) p. 163.

126. De hecho, es tan extremo Kauffman en la naturaleza necesariamente analógica del razonamiento aplicativo de las normas jurídicas que plantea que la prohibición de analogía que se plantea en materia penal es tan ingenua como lo prohibición de interpretación, la cual fracasó rotundamente tal como lo demuestra la historia. KAUFMANN (1976) p. 41.

127. JESCHECK (2002) p. 169. 
De esta manera, si se advierte que el legislador no es capaz de prever todos los casos posibles, pues entonces se asume que el juez conserva cierto margen de decisión para establecer si el caso encaja o no en el supuesto de hecho descrito en la disposición jurídica. En efecto, tan pronto se rechaza la ultrarracionalidad de legislador se está concediendo que la aplicación del derecho no implica un mero juicio lógico de subsunción, sino un razonamiento que también es, en alguna medida, valorativo ${ }^{128}$. El punto no consiste en excluir a la lógica del mundo del derecho y, menos aún, de la práctica interpretativa, sino poner de relieve que la selección de las premisas sobre las que el razonamiento discurre, centralmente depende de consideraciones valorativas $^{129}$. A su vez, lo dicho se desenvuelve a través de ese conjunto de reglas lógicas y paralógicas llamado sintéticamente 'lógica jurídica' ${ }^{130}$.

Así, lo que limita a la interpretación jurídica de las normas penales no es la 'mano muerta del pasado'; esto es, lo que pretendieron significar los que aprobaron una determinada formulación normativa. Lo que acota a la creatividad interpretativa es la cultura de los intérpretes, tal como lo plantea Jakobs ${ }^{131}$. La reconstrucción de las finalidades de las disposiciones jurídico-penales que hacen los intérpretes y que procuran encajar dentro de la sistemática del derecho penal y de las garantías constitucionales que lo informan.

Tales finalidades se pueden llegar a descubrir a través de una lectura o interpretación evolutiva de los bienes jurídicos involucrados que puede llegar a extender el ámbito de punición a supuestos no expresamente previstos en las formulaciones normativas, pero que resultan imprescindibles para asegurar su eficacia. Con todo, la eficacia no tiene la última palabra, sino que esta se ha de concebir como un esfuerzo por conciliar la finalidad de esa norma particular con la consistencia y coherencia de todo el sistema jurídico-penal.

En síntesis, la interpretación evolutiva de las normas penales no ha de pretender más que procurar que se cumpla con la finalidad de las disposiciones jurídico-penales; pero de una manera tal que no se perturbe al resto del sistema del derecho penal, desde sus garantías iusfundamentales hasta lo dispuesto en la parte especial y en el ordenamiento procesal penal.

128. LOMBARDI VALLAURI (1981) pp. 53-54.

129. SERNA BERMÚDEZ (2005) pp. 284-285.

130. KALINOWSKI (1973) [1965] p. 165. En un sentido similar, FERNÁNDEZ (1975) p. 121.

131. JAKOBS (1997) p. 103. 


\section{Conclusiones: armonizar la eficacia del ius puniendi bajo una subordinación a la vigencia material del principio de legalidad}

La interpretación de las leyes penales no implica necesariamente un compromiso con una noción de 'mano muerta del pasado'; es decir, la aplicación de disposiciones jurídico-penales no conlleva limitarse a seguir lo que expresamente plasmó el legislador histórico en una formulación normativa determinada.

En este trabajo se han propuesto lineamientos metodológicos para reconocer o descubrir cuáles son esas finalidades de las disposiciones jurídicas a través de una interpretación dinámica o evolutiva. En apretada síntesis, se trata de reconocer tendencias a través de convergencias en las expectativas que se extraen tanto de la jurisprudencia - que mira principalmente al pasado- como de la doctrina que pretende iluminar el faro de la práctica interpretativa del derecho penal con una perspectiva puesta en el futuro.

Asimismo, es importante reconocer que no todas las voces o actores institucionales tienen el mismo peso en lo que respecta a formar esas tendencias a las que me refería anteriormente. De lo que se trata es de examinar, caso por caso, sistema jurídico por sistema jurídico, a qué actores hay que atender primordialmente para reconocer aquellas expectativas que se depositan en la interpretación de las normas jurídicas.

Con todo, la interpretación dinámica presenta no pocas tensiones con el principio de legalidad penal. Ahora bien, ¿cómo se han de descomprimir esas tensiones entre interpretación dinámica o evolutiva del derecho penal y respeto al principio de legalidad? Pues asumiendo que el descubrimiento o reconocimiento de la finalidad de una norma penal supone procurar su eficacia, pero no a cualquier costo. De lo que se trata, en efecto, es de conciliar dos extremos; por un lado, (i) la materialización de lo que pretenden concretar las disposiciones jurídico-penales en términos de protección de bienes jurídicos y, por el otro, (ii) el sistema de garantías que establece el derecho penal para que su aplicación se ajuste a él.

Aquí es donde una directiva interpretativa sistemática juega su papel más importante. El punto consiste en argumentar sólidamente que la interpretación dinámica que se propone no es disruptiva o desestabilizadora, sino todo lo contrario: un instrumento para asegurar el equilibro del sistema jurídico-penal. Lo que está en juego consiste en armonizar la eficacia del ius puniendi con los principios configuradores del derecho penal - paz social y respeto de la dignidad de la persona humana - y, a la vez, una adecuación con el sistema de garantías que supone el derecho penal para proteger a la persona humana involucrada en un pleito de naturaleza penal; sea en calidad de víctima o de acusado.

Por ello, la aplicación de una metodología interpretativa dinámica no ha de ser usada a la ligera, sino bajo un criterio estrictamente restrictivo; esto es, en tanto y en cuanto sea imprescindible para concretar la eficacia de la protección de los bienes 
jurídicos a los que refiere cada tipo penal. De lo contrario, la interpretación dinámica se volvería una mera excusa para ampliar la discrecionalidad judicial al momento de aplicar la ley penal y se podría desembocar en una pendiente resbaladiza que llevaría directo hacia la prohibición de analogía. Dicho de otra manera, la armonización entre interpretación dinámica y concretización del principio constitucional de legalidad penal exige necesariamente que tal metodología interpretativa se emplee como última ratio para mantener la eficacia de la disposición jurídico-penal bajo interpretación.

En breve, la defensa de la interpretación dinámica no apunta a liberarnos del pasado, sino a no dejarnos sujetar incondicionalmente por él. Se pretende con esto colmar las expectativas depositadas al momento de instituir una formulación normativa; pero siempre bajo el respeto meticuloso de las garantías y principios fundamentales del derecho penal.

\section{Referencias bibliográficas}

ARGENTINA. C. S. J. N., "Jensen, Carlos c/ Provincia de Mendoza” (1922): Fallos 136:20o. Disponible en: http://sj.csjn.gov.ar/sj/tomosFallos.do?method=verTom oPagina\&tomo $=136 \&$ pagina $=200 \#$ page $=200$ [Fecha de consulta: 25 de mayo de 2020].

ARGENTINA. C. S. J. N., "Rolfo, Domingo Americo S/ Inf ley 17.250" (1979): Fallos 301:395. Disponible en: http://sjconsulta.csjn.gov.ar/sjconsulta/documentos/verDocumentoSumario.html?idDocumentoSumario=18934 [Fecha de consulta: 25 de mayo de 2020].

ARGENTINA. C. S. J. N., “Godoy, Roberto Carlos s/ ley 11.683” (1993): Fallos 316:1223, Disponible en: http://sjconsulta.csjn.gov.ar/sjconsulta/documentos/verDocumentoSumario.html?idDocumentoSumario $=4029$ [Fecha de consulta: 25 de mayo de 2020].

ARGENTINA. C. S. J. N., "Lambruschi, Pedro Jorge s/ ley 23.771" (1997): Fallos 320:227. Disponible en: http://sjconsulta.csjn.gov.ar/sjconsulta/documentos/verDocumentoSumario.html?idDocumentoSumario $=6387$ [Fecha de consulta: 25 de mayo de 2020].

ARGENTINA. C. S. J. N., "Relojerías Fernández S.C.A. s/ apelación clausura” (1997): Fallos 320:2649. Disponible en: http://sjconsulta.csjn.gov.ar/sjconsulta/documentos/verDocumentoSumario.html?idDocumentoSumario=6356 [Fecha de consulta: 25 de mayo de 2020 ].

ARGENTINA. C. S. J. N., "Simón, Julio Héctor y otros s/ privación ilegítima de la libertad" (2005): Fallos 328:2056. Disponible en: http://sjconsulta.csjn.gov.ar/sjconsulta/documentos/verDocumentoByIdLinksJSP.html?idDocumento=5863381\&ca che $=1590413995940$ [Fecha de consulta: 25 de mayo de 2020]. 
ARGENTINA. Juzgado Nacional de Primera Instancia en lo Criminal y Correccional Federal Nº 6 (1999a): "Lanata, Jorge S/ desestimación", La Ley 1999-C, 458.

ARGENTINA. Cámara Nacional de Apelaciones en lo Criminal y Correccional (1999b): Sala VI, “Lanata, Jorge S/ desestimación”, 04/o3/1999, La Ley 1999-C, 458.

BRASIL. TRIBUNAL SUPREMO FEDERAL, Inquérito 4.781 Distrito Federal, Relator: Min. Alexandre de Moraes (2019): Disponible en: http://www.stf.jus.br/arquivo/cms/noticiaNoticiaStf/anexo/inq4781.pdf.

CANADA. British Privy Council, "Edwards v. Attorney General of Canada" (1930), A.C. 124.

CORTE INTERAMERICANA DE DERECHOS HUMANOS. Opinión Consultiva OC-6/86, parr. 22. Disponible en: https://www.corteidh.or.cr/docs/opiniones/seriea_o6_esp.pdf.

ESTADOS UNIDOS DE AMÉRICA. “Towne v. Eisner, Collector of United States Internal Revenue for the Third District of the State of New York" (1918), 245 U.S. 418.

\section{Libros, capítulos de libro y artículos de doctrina}

ALLEN, Francis A. (1990): "A Crisis of Legality in the Criminal Law - Reflections on the Rule of Law". En Mercer Law Review, vol. 42, n 2, pp. 811-846.

ALONSO, Juan Pablo (2010): Interpretación de las normas y derecho penal (Buenos Aires, Del Puerto).

ARÓSTEGUI, Julio (2004): La historia vivida: sobre la historia del presente (Madrid, Alianza).

ATIENZA, Manuel (2013): Curso de argumentación jurídica (Madrid, Trotta).

BACIGALUPO, Enrique (1997): Principios de derecho penal: parte general. 1990 ( $4^{\circ}$ Ed., Madrid, Akal).

BACIGALUPO, Enrique (1999): Principios constitucionales de derecho penal (Buenos Aires, Hammurabi).

BACIGALUPO, Enrique (2005): Derecho Penal y el Estado de Derecho (Santiago de Chile: Jurídica de Chile).

BADENI, Gregorio (2005): "El caso "Simón" y la supremacía constitucional". En La Ley, tomo $D$, p. 639 y ss.

BADENI, Gregorio (2006): Tratado de derecho constitucional (Buenos Aires, La Ley, Vol. I). 
BECCARIA, Cessare (2017): Dei delitti e delle pene. 1764 (Roma, Castelvecchi).

BOBBIO, Norberto (2004): "La plenitud del orden jurídico y la interpretación". En Isonomía, vol. 21, 2004, pp. 255-260. Disponible en: http://www.scielo.org.mx/ pdf/is/n21/n21a9.pdf [Fecha de consulta: 06 de mayo de 2020].

BRENNAN, William J. (1985): "The Constitution of the United States: Contemporary Ratification". En South Texas Law Review, vol. 27, n 3, pp. 433-446.

BREWER-CARIAS, Allan R. (1995): Sistema mixto o integral de control de constitucionalidad en Colombia y Venezuela. (Bogotá, Universidad Externado de Colombia \& Pontificia Universidad Javeriana). Disponible en: http://allanbrewercarias. net/Content/449725d9-f1cb-474b-8ab2-41efb849fea5/Content/II.1.73.pdf [Fecha de consulta: o6 de mayo de 2020].

CANCIO MELIÁ, Manuel (2003): "¿Derecho penal del enemigo?" En CANCIO MELIÁ Manuel \& JAKOBS Günther (Ed.). Derecho penal del enemigo (Madrid, Civitas), pp. 59-101.

COTTA, Sergio (1991): Il diritto nell'esistenza. Linee di ontofenomenologia giuridica (Milano, Giuffrè).

CRUZ, Roberto (2020): Delitos instrumentales: aspectos de politica legislativa (Montevideo: B de F).

CREUS, Carlos (1999): "El miedo a la analogía y la creación de "vacíos" de punibilidad en la legislación penal (intercepción de comunicaciones telefónicas y apropiaciones de "e-mail")". En Jurisprudencia Argentina, vol. 6165.

DONNA, Eduardo A. (1996): Teoría del delito y de la pena (Buenos Aires, Astrea).

EDWARDS, Carlos E. (1996): Garantías constitucionales en materia penal (Buenos Aires, Astrea).

ELIAS, José Sebastián (20o8): "Constitutional Changes, Transitional Justice, and Legitimacy: The Life and Death of Argentina's Amnesty Laws". En Hastings International and Comparative Law Review, vol. 31, $\mathrm{n}^{\circ}$ 2, pp. 587-646. Disponible en: https://repository.uchastings.edu/hastings_international_comparative_law_review/vol31/iss2/3/ [Fecha de consulta: 06 de mayo de 2020].

ESSER, Josef (1961): Principio y norma en la elaboración jurisprudencial del derecho privado, (Barcelona, Bosch).

ESSER, Josef (1986): "La interpretación". En Anuario de filosofía del derecho, vol. 3, pp. 41-74. Disponible en: https://dialnet.unirioja.es/servlet/articulo? codigo $=142103$ [Fecha de consulta: o6 de mayo de 2020]. 
ETCHEVERRY, Juan B. (2020): "Una aproximación a los principios jurídicos desde su función de fundamentación". En Civilistica.com, vol 9, n 1, pp. 1-31. Disponible en: https://civilistica.emnuvens.com.br/redc/article/view/514 [Fecha de consulta: o6 de mayo de 2020].

FERNÁNDEZ, Alberto V. (1975): Arte de la persuasión oral: teórica y práctica de la comunicación por la palabra (Buenos Aires, Astrea).

FOUCAULT, Michel (2006): Seguridad, territorio, población: curso en el Collége de France (1977-1978): (Traducción de Pons, Horacio), (México D. F., Fondo de Cultura Económica).

FUENTES CONTRERAS, Édgar H. (2019): "Del Estado constitucional al Estado convencional de Derecho. Estudio Preliminar sobre el modelo del Estado Convencional de Derecho, en el contexto latinoamericano". En Revista Jurídica Digital UANDES, vol. 3, n 2, pp. 13-42. https://doi.org/10.24822/rjduandes.0302.

GALLANT, Kenneth S. (2009): The Principle of Legality in International and Comparative Criminal Law. (New York, Cambridge University Press). https://doi. org/10.1017/CBO9780511551826.

GOLDSWORTHY, Jeffrey (1994): "Implications in Language, Law and the Constitution". En G. Lindell (Ed.). Future Directions in Australian law: Essays in Honour of Professor Leslie Zines (Sydney: Australian National University), pp. 150-184.

GOLDSWORTHY, Jeffrey (2005): "Legislative Intentions, Legislative Supremacy, and Legal Positivism". En San Diego Law Review, vol. 42, n² 2, pp. 493-519.

GOLDSWORTHY, Jeffrey (2011): "Constitutional Implications Revisited". En University of Queensland Law Journal, vol. 30, n ${ }^{\circ}$, pp. 9-34.

GREY, Thomas C. (1974): "Do We Have an Unwritten Constitution?". En Stanford Law Review, vol. 27, n 3 , pp. 703-718.

GREY, Thomas C. (1984): "The Constitution as Scripture". En Stanford Law Review, vol. $37, \mathrm{n}^{\circ}$ 1, pp. $1-26$.

GREY, Thomas C. (1988): "The Uses of an Unwritten Constitution". En Chicago-Kent Law Review, vol. 64, $\mathrm{n}^{\circ}$ 1, pp. 211-238.

HALLEVY, Gabriel (2010): Modern Treatise on The Principle of Legality in Criminal Law (Heidelberg, Springer). https://doi.org/10.1007/978-3-642-13714-3.

HART, H. L. A. (1976): "American Jurisprudence through English Eyes: The Nightmare and the Noble Dream". En Georgia Law Review, vol. 11, n 5, pp. 969-99o. 
HASSEMER, Winfried (1989): Introducción a la criminología y al derecho penal (Valencia, Tirant lo Blanch).

HASSEMER, Winfried (1999): Persona, mundo y Responsabilidad (Bogotá, Temis).

HESSE, Konrad (1992): Escritos de derecho constitucional (Traducción de Cruz Villalón, Pedro), (2o Ed., Madrid, Centro de Estudios Constitucionales).

HIGHTON, Elena I. (2010): "Sistemas concentrado y difuso de control de constitucionalidad". En A. Von Bogdandy, E. F. Mac-Gregor, \& M. M. Antoniazzi (Eds.), La justicia constitucional y su internacionalizacion: ¿hacia un ius constitutionale commune en América Latina? (México D.F., Univ. Nacional Autónoma de Mexico), pp. 107-173.

HOLMES, Oliver Wendell (1896): "Path of the Law". En Harvard Law Review, vol. 10, $\mathrm{n}^{\circ} 8$, pp. $457-478$.

JAKOBS, Günther (1997): Derecho penal: parte general (20 Ed., Madrid, Marcial Pons).

JESCHECK, Hans-Heinrich (2002): Tratado de derecho penal: parte general. (Traducción de Olmedo Cardenete, Miguel), (Granada, Comares).

JIMÉNEZ DE ASÚA, Luis (1958): Principios de derecho penal: la ley y el delito (3a Ed., Buenos Aires, Abeledo-Perrot).

KALINOWSKI, Georges (1973): Introducción a la lógica jurídica: elementos de semiótica jurídica. (Traducción Juan A. Casaubón.), (Buenos Aires, EUDEBA).

KAUFMANN, Arthur (1976): Analogía y "naturaleza de la cosa”: hacia una teoría de la comprensión jurídica (Santiago de Chile: Editorial Jurídica de Chile).

KAUFMANN, Arthur (2005): "La espiral hermenéutica". En Persona y Derecho, vol. 52, pp. 405-410. Disponible en: https://dadun.unav.edu/handle/10171/14566 [Fecha de consulta: 06 de mayo de 2020].

KAVANAGH, Aileen (2003): "The Idea of a Living Constitution". En Canadian Journal of Law and Jurisprudence, vol. 16, pp. 55-90. https://doi.org/10.1017/ So841820900oo6639.

KOSELLECK, Reinhart (2004): Futures Past: On the Semantics of Historical Time (Traduccion de Tribe, Keith), (New York, Columbia University Press).

KOSELLECK, Reinhart (2010): historia-Historia (Traducción de Gomez Ramos, Antonio) (2da ed., Madrid, Trotta).

LAISE, Luciano D. (2017): El poder de los conceptos: convenciones semánticas y objetividad referencial en la interpretación constitucional originalista (Méjico D. F., Porrúa). 
LAISE, Luciano D. (2018): La interpretación evolutiva del concepto de "interés superior del niño": método interpretativo, presupuestos semánticos y dificultades. En Sapiens. Revista Universitaria de Investigación, vol. 19, pp. 12-30.

LAISE, Luciano D. (2019): "El constitucionalismo viviente: método interpretativo, presupuestos semánticos y dificultades". En Revista de Derecho Político, vol. 105, pp. $225-250$.

LESSIG, Lawrence (1994): "Understanding Changed Readings: Fidelity and Theory". En Stanford Law Review, vol. 47, n 3, pp. 395-472.

LEVINSON, Sanford (1979): “The Constitution" in American Civil Religion. En Supreme Court Review, vol. 1, pp. 123-152.

LEVINSON, Sanford (2003): "Why I Do Not Teach Marbury (Except to Eastern Europeans) and Why You Shouldn't Either". En Wake Forest Law Review, vol. 38, n ${ }^{\circ}$ 2, pp. 553-578.

LOMBARDI VALLAURI, Luigi (1981): Corso di filosofia del diritto (Padova, CEDAM).

MCCONNELL, Michael W. (1997): "Textualism and the Dead Hand of the Past. En George Washington Law Review", vol. 66, n 5 \& 6, pp. 1127-1142. Disponible en: https://chicagounbound.uchicago.edu/cgi/viewcontent.cgi?article $=12606 \&$ conte $\mathrm{xt}=$ journal_articles [Fecha de consulta: 06 de mayo de 2020].

MILLER, Arthur S. (1962a): "Notes on the Concept of the Living Constitution". En George Washington Law Review, vol. 31, pp. 881-918.

MILLER, Arthur S. (1962b): The Changing Role of the United States Supreme Court. The Modern Law Review, vol. 25, n 6, pp. 641-653.

MILLER, Arthur S.(1965): "On the Need for Impact Analysis of Supreme Court Decisions". En Georgetown Law Journal, vol. 53, n² 2, pp. 365-402.

MILLER, Arthur S. (1970): "Change and the Constitution". En Law and the Social Order, s/i, pp. 231-255.

MILLER, Arthur S. (1972): "Legal Foundations of the Corporate State". En Journal of Economic Issues, vol. 6, $\mathrm{n}^{\circ}$ 1, pp. 59-79.

MILLER, Arthur S. (1979): "The Elusive Search for Values in Constitutional Interpretation". En Hastings Constitutional Law Quarterly, vol. 6, n² 2, pp. 487-510.

MILLER, Arthur S. (1982): "Toward a Definition of "the" Constitution". En University of Dayton Law Review, vol. 8, $\mathrm{n}^{\circ}$ 3, pp. 633-712.

MILLER, Arthur S. (1983): "Social Justice and the Warren Court: A Preliminary Examination". En Pepperdine Law Review, vol. 11, n 3, pp. 473-498. 
MILLER, Arthur S. (1989): Reason of State and the Emergent Constitution of Control. Minnesota Law Review, 64(3), 585-634.

MIR PUIG, Santiago (1994): El derecho penal en el estado social y democrático de derecho (Barcelona, Ariel).

MIR PUIG, Santiago (2006): Derecho penal: parte general ( $8^{\circ}$ Ed., Barcelona, Reppertor).

MONTERO AROCA, Juan (2016): Principios del proceso penal: una explicación basada en la razón (Buenos Aires, Astrea).

MONTORO BALLESTEROS, Manuel Alberto (2001): "La seguridad jurídica en la configuración del Derecho como ordenamiento". En Anuario de filosofía del derecho, vol. 18, pp. 301-320. Disponible en: https://dialnet.unirioja.es/descarga/articulo/257667.pdf [Fecha de consulta: o6 de mayo de 2020].

MOORE, Michael S. (1989): "Do We Have an Unwritten Constitution?", En Southern California Law Review, vol. 63, n 1, pp. 107-140.

MOORE, Michael S. (200o): Justifying the Natural Law Theory of Constitutional Interpretation. Fordham Law Review, vol. 63, n 5, pp. 2087-2118. Disponible en: https://ir.lawnet.fordham.edu/cgi/viewcontent.cgi? article $=3720 \&$ context $=$ flr $[\mathrm{Fe}-$ cha de consulta: o6 de mayo de 2020].

MÜLLER, Ingo (1987): Los juristas del horror. La "justicia” de Hitler: el pasado que Alemania no puede dejar atrás (Traducción, Figueredo, Carlos A.), (Bogotá, Alvaro Nora).

NINO, Carlos S. (1980): Los limites de la responsabilidad penal: una teoría liberal del delito (Buenos Aires, Astrea).

PERISTERIDOU, Christina (2015): "Three Models of Criminal Justice". En C. Peristeridou (Ed.), The Principle of Legality in European Criminal Law (Cambridge, Intersentia), pp. 129-174. https://doi.org/DOI: 10.1017/9781780685625.005.

PERRY, Michael J. (1985): "The Authority of Text, Tradition, and Reason: A Theory of Constitutional Interpretation". En Southern California Law Review, vol. 58, $\mathrm{n}^{\circ} 1$ \& 2, pp. 551-602.

RABBI-BALDI CABANILLAS, Renato (2020): Interpretación jurídica (Buenos Aires, Astrea).

RAZ, Joseph (2003): "About Morality and the Nature of Law". En The American Journal of Jurisprudence, vol. 48, n 1, pp. 1-15. https://doi.org/10.1093/ajj/48.1.1 
REHNQUIST, William (1976): "Notion of a Living Constitution". En Texas Law Review, vol. $54, \mathrm{n}^{\circ} 4$, pp. 693-706.

ROSLER, Andrés (2017): "Si Ud. quiere una garantía, compre una tostadora”: acerca del punitivismo de lesa humanidad". En En Letra: Derecho Penal, vol. 3, $\mathrm{n}^{\circ}{ }_{5}$, pp. 62-102. Disponible en: http://www.pensamientopenal.com.ar/system/files/2018/o2/doctrina46254.pdf [Fecha de consulta: o6 de mayo de 2020].

ROSLER, Andrés (2018): "Hermes o la continuación de Antígona por otros medios. Una crítica del interpretativismo". En Revista Jurídica de la Universidad de San Andrés, vol. 6, pp. 1-27. Disponible en: https://www.udesa.edu.ar/sites/default/ files/rosler_hermes_y_antigona_pdf.pdf [Fecha de consulta: 06 de mayo de 2020].

ROSLER, Andrés (2019): La ley es la ley: autoridad e interpretación en la filosofía del derecho (Buenos Aires, Katz).

ROXIN, Claus (1997): Derecho penal: parte general. (Traducción de Luzón Peña, Diego Manuel), (Madrid, Civitas).

RUBENFELD, Jed (1997): "Moment and the Millennium". En George Washington Law Review, vol. 66, $\mathrm{n}^{\circ} 5$ \& 6, pp. 1085-1111.

SAGÜÉS, Nestor P. (2016): La Constitución bajo tensión (Querétaro, Instituto de Estudios Constitucionales de Estado de Querétaro). Disponible en: https://archivos. juridicas.unam.mx/www/bjv/libros/10/4754/1.pdf [Fecha de consulta: o6 de mayo de 2020].

SERNA BERMÚDEZ, Pedro (2005): "Hermeneútica y relativismo. Una aproximación desde el pensamiento de Arthur Kaufmann". En P. Serna (Ed.), De la argumentación jurídica a la hermenéutica: revisión crítica de algunas teorías contemporáneas (2a Ed., Granada, Comares), pp. 279-316.

SILVA SÁNCHEZ, Jesus-María (1992): Aproximación al derecho penal contemporáneo (Barcelona, Bosch).

SILVA SÁNCHEZ, Jesus-María (2006): "Sobre la interpretación “teleológica” en derecho penal". En M. Díaz y García Conlledo \& J. A. García Amado (Eds.), Estudios de filosofía del derecho penal (Bogotá, Universidad Externado de Colombia), pp. 365-395.

SILVA SÁNCHEZ, Jesus-María (2008): "La interpretación de las leyes y la cultura de los juristas". En A. J. C. Lynnet, Eduardo Montealegre; John (Ed.), Sistema penal normativista en el mundo contemporáneo. Libro homenaje al Profesor Günther Jakobs en su 700 aniversario (Bogotá, Universidad Externado de Colombia), pp. 201-213. 
VON LISZT, Franz (1970): Über den Einfluss der soziologischen und anthropologischen Forschungen auf die Grundbegriffe des Strafrechts. En Strafrechtliche Vorträge und Aufsätze (Berlin, Walter de Gruyter), pp. 75-93.

WALUCHOW, Will (2005): "Constitutions as Living Trees: An Idiot Defends". En Canadian Journal of Law and Jurisprudence, vol. 18, $\mathrm{n}^{\circ}$ 2, pp. 207-248. https://doi. org/10.1017/So841820900o03994.

WALUCHOW, Will (2007): A Common Law Theory of Judicial Review: The Living Tree (New York, Cambridge University Press).

YACOBUCCI, Guillermo J. (2002): El sentido de los principios penales (Buenos Aires, Abaco).

YACOBUCCI, Guillermo J. (2006): "El dilema de la legalidad en el Derecho penal". En M. Cancio Meliá (Ed.), Derecho penal del enemigo: el discurso penal de la exclusión (Madrid: Edisofer \& BdeF), pp. 1073-1116.

ZAFFARONI, Eugenio Raúl (1987): Tratado de derecho penal: parte general (Buenos Aires, Ediar).

ZAFFARONI, Eugenio Raúl (1998): En busca de las penas perdidas (Buenos Aires, Ediar).

ZAMBRANO, Pilar (2009a): La inevitable creatividad en la interpretación jurídica: una aproximación iusfilosófica a la tesis de la discrecionalidad (Mexico D. F., Instituto de Investigaciones Jurídicas, U. N. A. M). Disponible en: http://ru.juridicas. unam.mx/xmlui/handle/123456789/116oo [Fecha de consulta: o6 de mayo de 2020].

ZAMBRANO, Pilar (2009b): "Los derechos ius-fundamentales como alternativa a la violencia: entre una teoría lingüística objetiva y una teoría objetiva de la justicia". En Persona y Derecho, vol. 6o, pp. 131-152. Disponible en: https://dadun.unav.edu/ handle/10171/17505 [Fecha de consulta: o6 de mayo de 2020]. 